\title{
PRIMEROS RESULTADOS DE LAS EXCAVACIONES REALIZADAS EN LA VILLA DE LA ESTACIÓN (ANTEQUERA, MÁLAGA)
}

\author{
POR \\ MANUEL ROMERO \\ Arqueólogo municipal del Excmo. Ayuntamiento de Antequera \\ IRENE MAÑAS \\ Universidad Complutense de Madrid \\ SEBASTIÁN VARGAS \\ Consejo Superior de Investigaciones Científicas
}

\section{RESUMEN}

El artículo describe y realiza un primer estudio de las estructuras y los materiales de una villa romana recientemente excavada en Antequera. Entre ellos destacan el repertorio musivo y escultórico, de los que emerge la importancia del yacimiento.

\section{SUMMARY}

The present article describes and attempts a first approach to the structures and materials from a recently discovered Roman Villa in Antequera. The Villa is particularly remarkable for its mosaics and sculptures, from which the importance of the site arises.

PALABRAS CLAVE: Bética romana. Villa romana. Termas. Arquitectura. Mosaicos. Esculturas. Antequera. Málaga.

KEY WORDS: Roman Baetic. Roman Villa. Baths. Architecture. Mosaics. Sculptures. Antequera. Málaga.

Las intervenciones arqueológicas llevadas a cabo recientemente en la Villa romana de la Estación (Antequera, Málaga) están contribuyendo de forma decisiva a la exhumación de parte de un excepcional conjunto de la provincia Bética. Los hallazgos han sido tan importantes que, aunque los trabajos arqueológicos no han finalizado, hemos estimado conveniente realizar un estudio preliminar de los mismos, conscientes de que constituyen sólo una parte de este gran yacimiento, cuyo estudio pormenorizado daremos a conocer cuando se concluyan definitivamente las excavaciones.

\section{INTRODUCCIÓN}

El yacimiento ocupa la ladera media y baja del cerro llamado "del Parador", límite norte del actual casco ubano de Antequera, junto a la N-331, con cota media de $472 \mathrm{~m}$ sobre el nivel del mar. En su entorno inmediato destacan dos caminos históricos: por el este, el camino de Quintana y por el oeste, el denominado camino de los Sillares ${ }^{1}$.

Las características topográficas confieren al yacimiento una localización inmejorable, dominando la vega antequerana y controlando las principales rutas de comunicación que existían en la Antigüedad desde el interior hacia la costa malagueña ${ }^{2}$. El establecimiento también cumple a la perfección con los requisitos indispensables de la habitabilidad -amoenitas- que los agrónomos latinos consideraban necesarios en la ubicación de una villa: salubridad y amabilidad del paraje, amplio dominio visual y belleza del paisaje, orientación adecuada y abundancia de agua (Catón, De agricult. I, 1, 3). De esta manera, resulta fácil comprender la elección de este enclave para la construcción de una villa de carácter semiurbano o de una mansio, conjugando el hecho de ser un centro residencial y un núcleo de explotación agrícola en un gran fundus en la vega antequerana.

La existencia del yacimiento es conocida desde principios del siglo pasado ${ }^{3}$. La primera intervención arqueo-

\footnotetext{
1 Romero Pérez y Melero García 2001 y Melero García y Romero Pérez 2001.

2 Atencia Páez y Serrano Ramos 1980. Más reciente la publicación de Gozalbes Cravioto 1984.

3 R. Amador de los Ríos nos proporciona una noticia sobre restos de mosaicos hallados en el lugar (de los Ríos 1908: 164). Pero será en 1948, con motivo de los movimientos de tierra realizados durante las obras de ampliación en la carretera Antequera-Córdoba que seccionaron en dos mitades el yacimiento, cuando Simeón Giménez Reyna y Antonio García y Bellido realicen un primer acercamiento arqueológico a los restos a raíz de la aparición de un busto -tradicionalmente atribuído a Drusus Maior y recientemente identificado como Nero Germánico (León Alonso 2001: 280-285), un bronce de Cástulo y un mosaico (Giménez Reyna y García y Bellido 1948: 55). Posteriormente, Rafael Atencia Páez realizará un estudio de los restos que quedaron visibles en el arcén oeste de la mencionada carretera (Atencia Páez 1979: 247-261).
} 


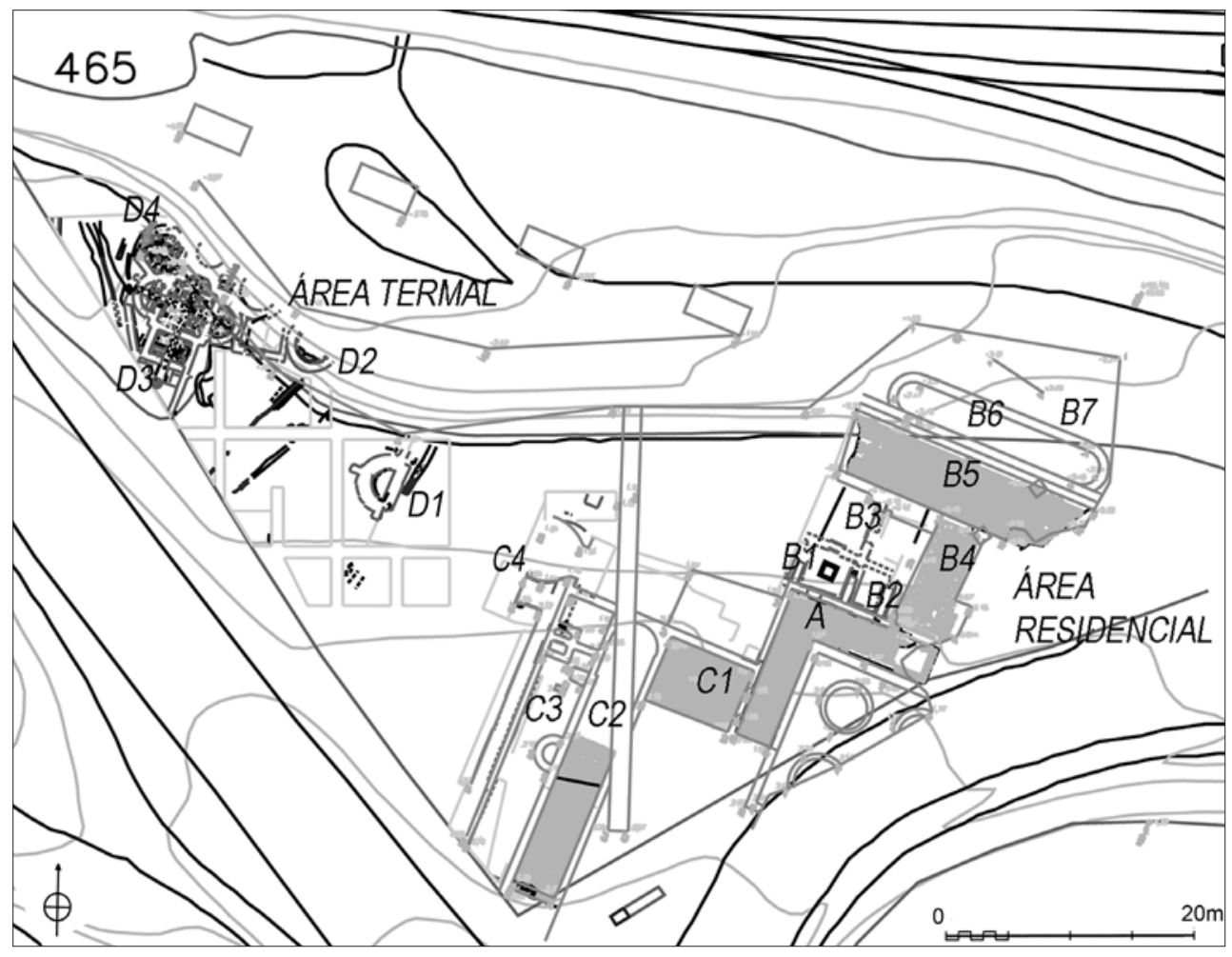

Figura 1. Planta general de la villa después de la intervención de 2005.

lógica de urgencia en el yacimiento fue planteada en 1998, en origen, a causa de las obras de construcción de la carretera de circunvalación norte de Antequera, cuyo trazado propuesto afectaba al bien en su totalidad y en cumplimiento de las cautelas arqueológicas contempladas en el PGOU vigente de Antequera. A la luz de los primeros resultados arqueológicos, la administración autónoma en coordinación con la municipal optó por desviar provisionalmente el trazado propuesto de la infraestructura a su paso por el yacimiento, incluso por no concluir la obra viaria en este punto.

La segunda intervención en el yacimiento (20052006), de carácter preventivo, ha tenido como objetivo prioritario la documentación exhaustiva de los restos arqueológicos, ya sean estructurales o depósitos, para poder dictaminar su grado de conservación y las posibilidades de compatibilidad de la obra pública con los restos arqueológicos. También se ha llevado a cabo la delimitación completa del yacimiento arqueológico para descartar o en su caso respaldar posibles alternativas que pudieran surgir como propuestas para finalizar la obra viaria inconclusa desde 1998. Los resultados de estas intervenciones permiten reconocer la importancia del conjunto arquitectónico, aunque hasta ahora sólo conozcamos de manera parcial su desarrollo urbanístico y su integración económica con el paisaje.

\section{LOS RESTOS EDILICIOS}

Hasta el momento, la parte conocida de la villa corresponde sólo a zonas residenciales (pars urbana) bien identificadas mediante indicadores como pavimentos musivos ${ }^{4}$, un ninfeo exento y un área termal, situadas ambas al NW del edificio principal (fig. 1). Todas las estructuras se orientan siguiendo un eje perfecto en sentido NW-SE. Las áreas de trabajo (pars rustica of frumentaria), consustanciales a la propia naturaleza de la villa, pudieron ubicarse al oeste del conjunto excavado, según parecen indicar los resultados de las prospecciones llevadas a cabo al otro lado de la carretera N-331.

Los restos arqueológicos emergentes hasta este momento permiten intuir que el conjunto se acoge bien al tipo de villa romana de peristilo ${ }^{5}$. Es el gran espacio central el que ejerce de centro vertebrador de la planificación arquitectónica del edificio principal, dando acce-

4 En otras villas romanas del área aparece también una extensa decoración musiva ocupando las áreas residenciales, como en el caso de las del Cortijo de Auta (Riogordo, Málaga) (Boto González y Riñones Carranza 1990), o Torre de Benagalbón (Rincón de la Victoria, Málaga; Salado Escaño 2005).

5 Gorges 1979:109-151; Fernández Castro 1982: 60-77. 


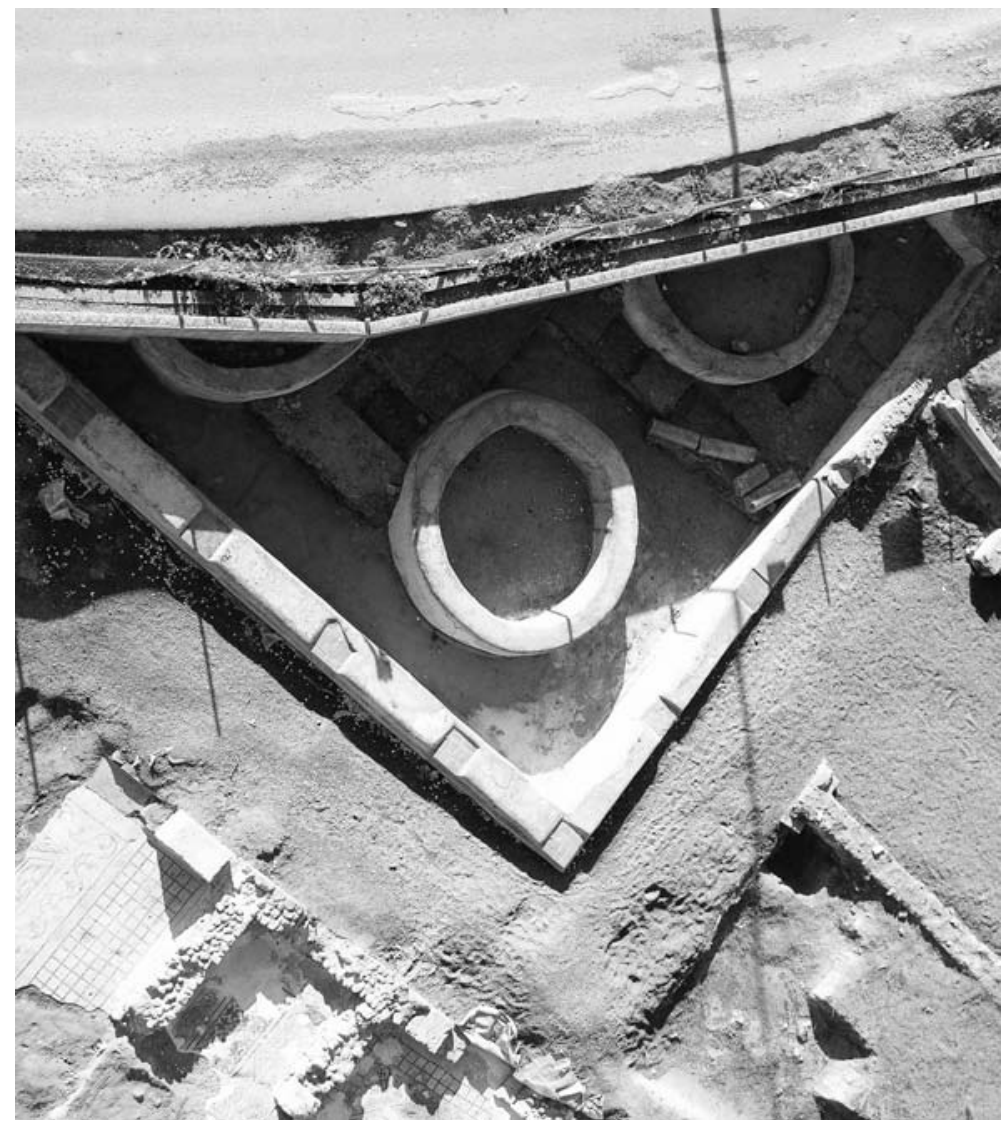

Figura 2. Peristilo (A) y estanque central.

so desde ambas galerías a varios espacios destinados probablemente a albergar en su mayor parte salas de representación y recepción ${ }^{6}$. Responde a una tipología abundantemente documentada en villas hispanorromanas y con un importante predominio en la Bética ${ }^{7}$, por lo que se nos antoja interesante comenzar la descripción de las diferentes estructuras a partir de este elemento.

\section{A. Peristilo}

Las excavaciones han puesto al descubierto las galerías norte y oeste de un peristilo porticado (A), cerrado por un muro continuo sobre el que apoyaban seis columnas de orden corintio en cada lado (fig. 2). Sobre el muro oeste

6 Balmelle 2001: 125.

7 Villas del Faro de Torrox (Málaga); Bruñel (Quesada, Jaén); Sabinillas (Manilva, Málaga); Villa del Santiscal (Cádiz); Villa de Rio Verde, Marbella (Málaga); Calle Primavera (Granada). Sobre las villas romanas de esta área puede verse un reciente estudio (Fornell Muñoz 2005: 39-50) que recoge la bibliografía principal. se conserva una basa in situ, mostrando el sistema de apoyo de las columnas, que se sitúan sobre plataformas de ladrillo colocadas en un rebaje del muro. El interior del muro presentaba, en el breve tramo descubierto en su cara sur, restos de revestimiento pictórico que están siendo estudiados actualmente por el equipo de restauración.

El corredor tiene unas medidas de 3,2 $\mathrm{m}$ de ancho $\mathrm{x}$ $12 \mathrm{~m}$ de longitud en el lateral norte y $13 \mathrm{~m}$ en el lateral oeste. La totalidad de lo excavado presenta una pavimentación en mosaico aparentemente continua. La banda de enlace está decorada mediante una hilera de rombos decorados dispuestos entre peltas afrontadas ${ }^{8}$. En el interior de estos rombos se alternan diferentes motivos decorativos: nudos de Salomón, guiloches, peltas afrontadas dentro de un círculo, rombos concéntricos o cruces. En el lateral oeste se despliega una composi-

8 Ornamentación de influencia africana muy frecuente en el sur de la península ibérica como decoración de orlas. Los Torrejones, Jumilla, Murcia (CME IV, n.56, fig. 22) s. IV; Villa de Panes Perdidos (Solana de Barros, Badajoz; Álvarez Martínez y Nogales Basarrate 1995: lám. 6,1 S. IV) s. IV. 


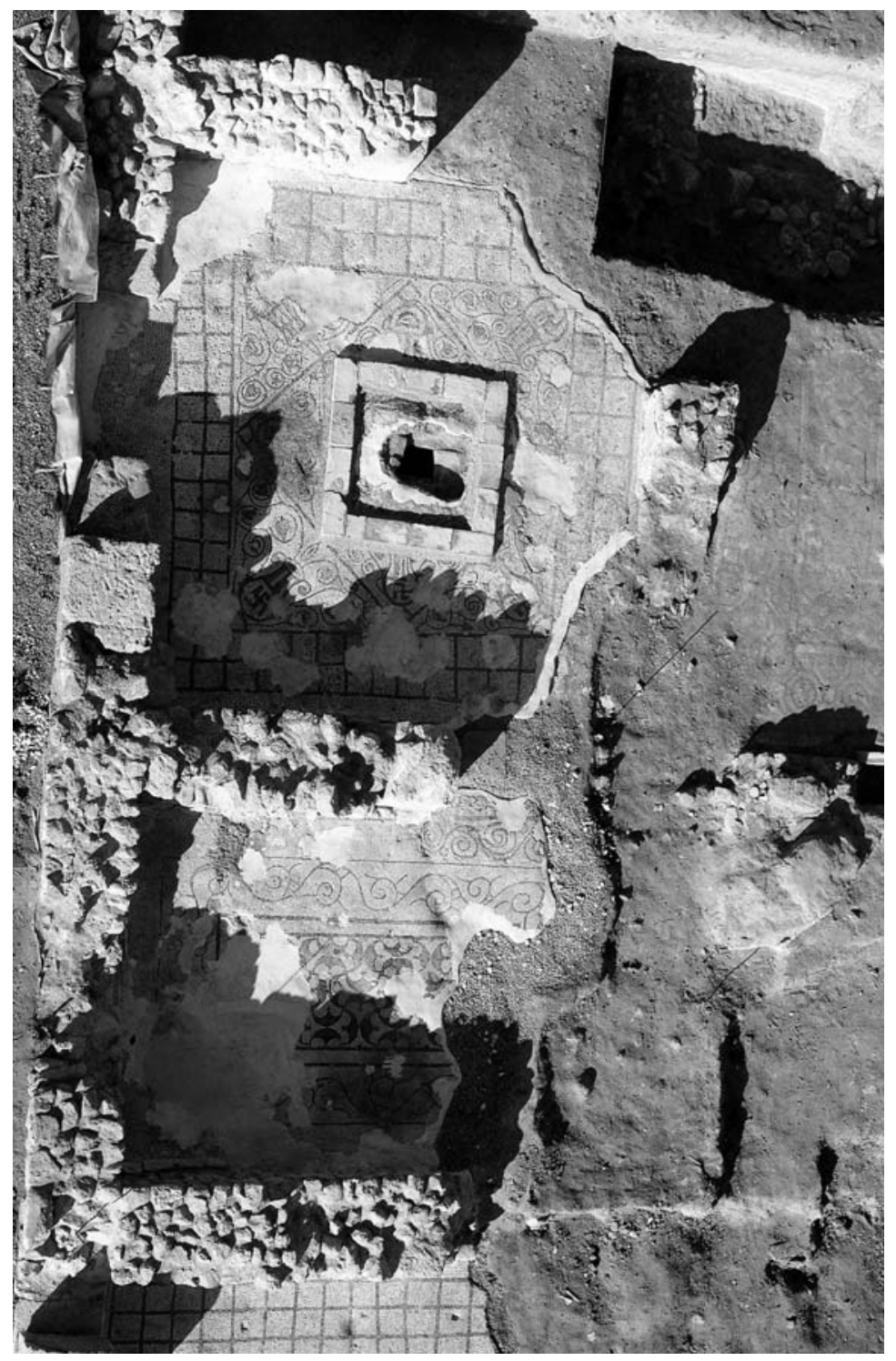

Figura 3. Espacios B1 (distribuidor), B2 y B3.

ción de dos cuadrados entre pares de peltas afrontadas 9 . Estos cuadrados quedan unidos entre sí por cuadripétalos lanceolados que a su vez encuadran cruces de Malta. El corredor norte del peristilum exhibe idéntico desarrollo hasta los $5 \mathrm{~m}$ de longitud donde, sin razón aparente,

9 Villa de Panes Perdidos (Solana de Barros, Badajoz; Álvarez Martínez y Nogales Basarrate 1995, lám. 6,2) s. IV; Yecla, Murcia (CME IV, n.67, fig. 26) mitad s. IV; Mosaico de las Cuatro Estaciones (Córdoba; CME IV, n. 19, láms. 22-23) época constantiniana; Villa de Puente de la Olmilla (Albaladejo, Ciudad Real; García Bueno 1994: 105, n. 3, fig. 5) segunda mitad s.IV. sustituye los dos cuadrados por tres y modifica la decoración en nudo de Salomón por el ajedrezado polícromo.

Los brazos del corredor envuelven una estructura parcialmente excavada, de planta cuadrada, cubierta enteramente por opus signinum y sellada en todos sus ángulos y bordes a través de un matacán de sección circular. Según los distintos indicios, podría responder a los restos de un gran estanque. En su interior albergaría cuatro grandes tazas $(1,20 \mathrm{~m}$ de altura media $\mathrm{x} 3,5 \mathrm{~m}$ de diámetro) de las cuales, por el momento, sólo pueden apreciarse enteramente dos. Probablemente fueron utilizadas como jardineras, alcorques, o para contener algu- 


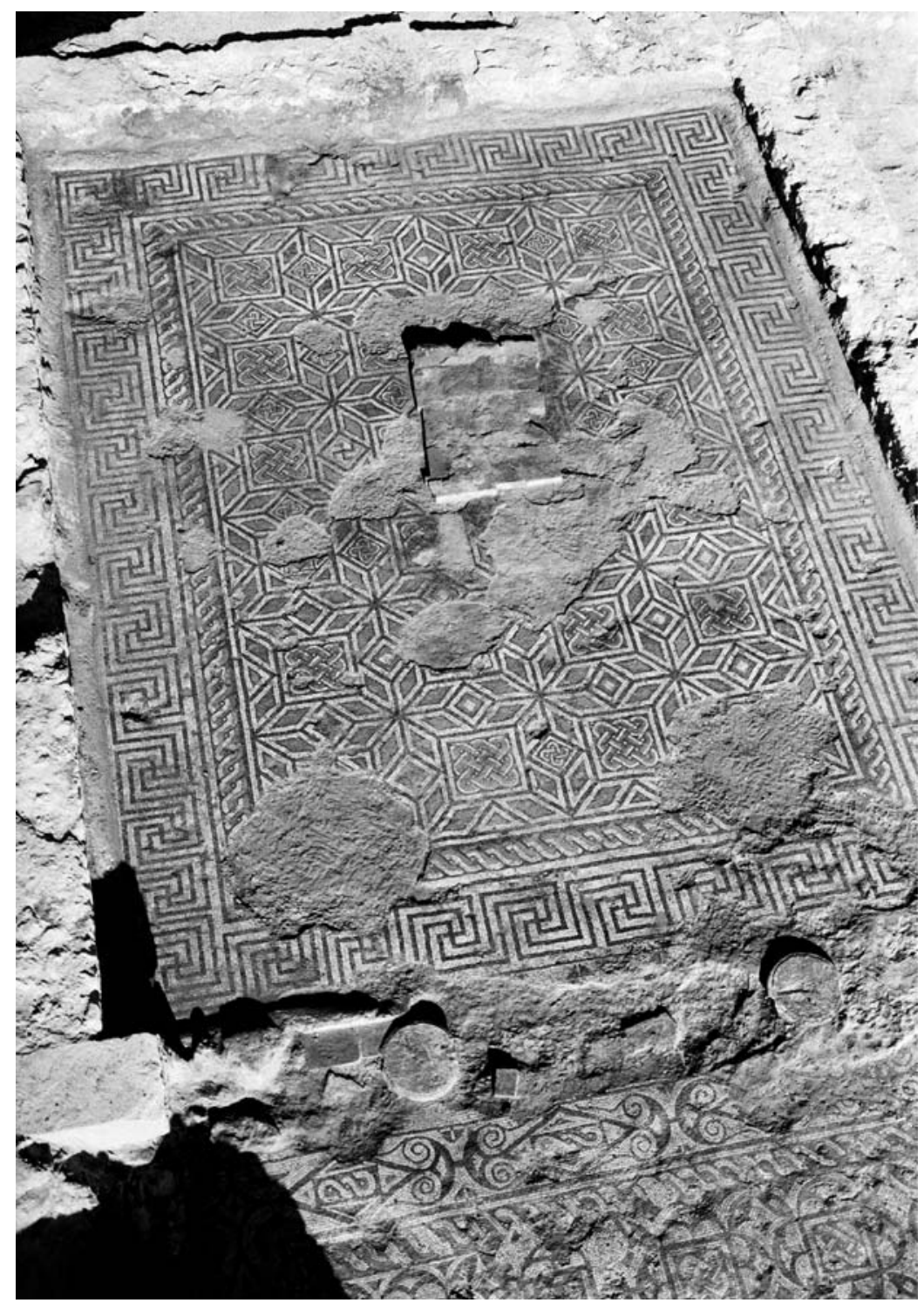

Figura 4. Espacio C1.

na escultura, puesto que carecen de revestimiento hidráulico en su interior ${ }^{10}$.

\section{B. Espacios en el ala norte del peristilo}

En la campaña de 2005-2006 salieron a la luz varios espacios dotados de cierta unidad arquitectónica y deco-

\footnotetext{
${ }^{10}$ La estructura circular del SO del estanque, que estratigráficamente se ha excavado en su totalidad, no ha proporcionado restos de derrumbe que pudieran pertenecer al muro, por lo que queda claro su colmatación de tierra vegetal en origen.
}

rativa (fig. 3). Este núcleo se compone de un espacio descubierto (B1) que tiene acceso desde el peristilo y al menos de dos habitaciones (B2 y B3). Todos los ambientes fueron construidos con muros de opus incertum de piedra caliza, unida con mortero de cal y arena. En ellos se repiten tipos pavimentales, motivos ornamentales y colores (negro, blanco, rojo y ocre). Esto se traduce, a nuestro entender, en una evidente unidad funcional.

B1. Espacio B1: Posee unas medidas de $3,92 \mathrm{~m} \mathrm{x}$ 3,79 m. Probablemente se encontraba sólo parcialmente cubierto. Este espacio comunicaba el peristilo (situado al sur) con al menos otras dos habitaciones situadas al norte 
y al este ${ }^{11}$, a través de vanos marcados mediante sillares de arenisca. Los muros interiores de la estancia estaban revestidos con pintura mural, hoy muy deteriorada.

La habitación está pavimentada con un mosaico polícromo, que presenta en toda su extensión algunas lagunas aisladas. El centro se encuentra perdido a causa de la posterior construcción de una posible fuente que se erige rompiendo el pavimento y aprovechando el canal de desagüe previamente existente bajo el suelo. Una banda de enlace blanca con decoración de retícula de cuadros negros enmarca un tapiz en el que se inscriben, sucesivamente, tres cuadrados por la punta. En los espacios angulares figuran cráteras, decoradas con esvásticas o semicírculos, de las que brotan tallos formando roleos con hojas de hiedra, motivo también ampliamente documentado en la musivaria romana desde el s.II d.C ${ }^{12}$. Esta realización en forma de estrella de cuadros inscritos, con símbolos tradicionalmente benéfico, como cráteras con cruces gamadas en los ángulos, gozó de una gran aceptación durante la Antigüedad tardía ${ }^{13}$. El mosaico debe fecharse por paralelos durante la primera mitad del s. IV.

Con posterioridad a la realización de la alfombra musiva, se encaja una pequeña fuente de planta cuadrada, que rompe el pavimento en el centro de la habitación. La nueva fuente tiene un canal de desagüe subterráneo de sección cuadrada de 0,40 m de ancho. En el centro de la misma se localizaría un surtidor, posiblemente una escultura de pequeño tamaño ${ }^{14}$.

En el nivel de derrumbe de la habitación y en el interior de la canalización se ha exhumado un número importante de plaquitas correspondientes a un opus sectile, similares a las que forman parte de la placa de sectile parietal con tema vegetal y de ave descubierta en la primera campaña (1998) ${ }^{15}$. Por tanto no descartamos, en principio, que la habitación presentara este tipo de decoración.

\footnotetext{
${ }^{11}$ La rotura del muro oeste no nos permite asegurar la existencia de otro vano, aunque el desarrollo de la alfombra musiva en este sector nos ayuda a suponer la existencia de otra habitación perteneciente a este mismo núcleo, conociéndose otra habitación aún no excavada al norte.

${ }^{12}$ Alcolea (Córdoba; CME III, n 23. lám. 32) s.II; Libreros (Vejer, Cádiz; CME IV, n. 50, lám. 41-42) s. IV. En la Meseta Castellana aparecen con mucha frecuencia en las grandes villas latifundistas fechadas principalmente en el siglo IV d.C. Baste citar los ejemplos vallisoletanos de la Villa del Prado y de Almenara de Adaja o el navarro de Liédena.

${ }^{13}$ Libreros (Vejer, Cádiz; CME IV, n. 50, lám. 41-42) s. IV; Vilches (Jaén; Bláquez et alii 1987: fig. 1).

${ }^{14}$ Una fuente de dimensiones parecidas apareció en la "Villa Romana del Cortijo de los Vila" en el cercano pueblo de Alameda (Loza Azuaga 1993: 178-179).

15 Gutiérrez Deza 2005: 379-394.
}

Todo parece indicar que nos encontramos ante un pequeño atriolo abierto por el sur al gran peristilo de la villa. Su función sería, por tanto, la de ventilar e iluminar las habitaciones circundantes. Aunque siempre resulta arriesgado atribuir funciones a los espacios, es probable que nos hallemos ante varios cubicula ${ }^{16}$. Su orientación nos indica que son estancias de verano, pues el único sol que incide directamente en esta época del año es el del atardecer. Los vanos abiertos a las habitaciones que rodean esta estancia también refuerzan esta hipótesis de patio distribuidor ${ }^{17}$.

B2. Espacio B2: Las dimensiones de esta estancia son sólo conocidas con certeza en su lado sur $(2,55 \mathrm{~m})$ cerrado al peristilo. El pavimento es un mosaico en oposición de colores blanco y negro. Presenta una gran laguna que afecta a casi un tercio de la superficie del mosaico. La alfombra central, rectangular, está decorada con una composición ortogonal de pares de peltas tangentes adosadas, alternativamente horizontales y verticales, rematadas en cruces. El motivo de peltas enfrentadas es muy común en todo el Mediterráneo a partir del s. I d.C. y hasta el IV como decoración de superficies extensas y de orlas ${ }^{18}$. Completan el mosaico una cenefa blanca con roleos filiformes negros sin remate de hojas y una banda de enlace sin decoración. En el mosaico se aprecian varias restauraciones, realizadas en materiales diversos.

B3. Espacio B3: Excavado parcialmente, por lo que los datos que traemos a colación tienen un carácter provisional. La habitación está ubicada al norte del atriolo, o espacio B1 y su límite septentrional lo constituye la gran galería o habitación B5. Las dimensiones que conocemos hasta el momento son de 5,20 m x 4,1 m. El tránsito hacia la estancia este, aún no excavada, se realizaba a través de un vano marcado por una moldura de mármol rosáceo. Las paredes de la estancia estarían decoradas con placas marmóreas que han aparecido en los niveles de derrumbe. La estancia aparece, al igual que las anteriores, pavimentada con un mosaico del que por el momento sólo pueden apreciarse las cenefas exteriores, presentando similitudes compositivas y técnicas con los vistos anteriormente.

Por el oeste, la habitación se cierra con un muro del que tan sólo nos han llegado las trazas de cimentación

${ }^{16}$ Sobre las varias utilidades del cubiculum, no sólo como dormitorio, en la casa romana vid. Riggsby 1997.

${ }^{17}$ Sin duda alguna el paralelo más significativo y cercano de este tipo de patios lo tenemos en las italicenses domus de Casa de los Pájaros y Casa del Planetario (Caballos Rufino; Marín Fatuarte; Rodríguez Hidalgo 1999) y en la Villa de Sabinillas (Málaga; Posac Mon y Rodríguez Oliva 1979).

${ }^{18}$ En la Bética se halla en varios ejemplares: Itálica (CME II n. 2, láms. 8-10) s. II; Manilva (CME III, n. 70, lám. 77) s. III; Córdoba (CME III, 99, n. 70, lám. 77) s.II; Villa del Ruedo (Hidalgo Prieto 1991: 325, n. 7, lám. XIV) s.III. 
por debajo de la cota del mosaico. Desconocemos por completo cómo se ha originado una patología tan curiosa, que ha provocado el fuerte buzamiento del mosaico hacia este lateral. Lo que sí podemos afirmar, en el estado actual de la investigación, es que el muro oeste de la estancia desaparece hasta la segunda hilada de cimentación, apareciendo una zanja donde el mosaico se desborda, literalmente, adquiriendo un perfil en forma de "U". Los materiales de la unidad estratigráfica que aparecen sobre esta patología nos induce a datarla en el momento de abandono de la villa, en torno a la primera mitad del siglo VI d.C.

Las siguientes estancias del ala norte del peristilo aparecieron en la campaña 1997-1998 y pueden ponerse en relación con el conjunto galería-ninfeo del extremo norte de la casa.

B4. Espacio B4: En el lateral norte del peristilo se abre un acceso con el borne metálico in situ, que da entrada a una nueva estancia de la que se ha excavado un espacio que funciona como corredor, de unos $9 \mathrm{~m}$ de longitud x 3,5 m de ancho. La particularidad de este espacio consiste en su construcción en rampa, evitando así el escalonamiento. Los trabajos de conservación del ninfeo (B6), desarrollados durante 2002, demuestran que bajo el nivel de la cama del mosaico existe una canalización que recoge el agua de la fontana del peristilo y la conduce hasta el ninfeo o estanque biabsidado. Esta habitación se pavimenta también mediante un mosaico, actualmente roto en parte de su superficie. Por los restos puede deducirse que el mosaico pertenece a la categoría de los llamados "en T", cuyos lados menores, a la manera de pasillos secundarios, forman un reticulado igual al de B1. La banda exterior consiste en una orla ancha en la que se desarrolla una línea de peltas contrapuestas y que cuenta con numerosos paralelos en la Hispania meridional ${ }^{19}$. El panel central esta formado a partir de dos grandes octógonos muy irregulares, separados por un meandro de esvásticas en trenza de dos cabos que albergan motivos decorativos como nudos de Salomón o flores de loto. Dicho meandro genera, además, unas superficies trapezoidales decoradas a partir de unos trapecios ornados en su interior por peltas con volutas. En el centro de su extremo norte, el mosaico en rampa presenta las huellas de un encaje rectangular y revestido de opus signinum con unas dimensiones de $0,35 \mathrm{~m} \mathrm{x} 0,23$ $\mathrm{m}$, que fue realizado después de la construcción del mosaico. Probablemente fuera utilizado para situar un herma.

B5. Galería porticada: Se trata de un gran espacio, sólo parcialmente excavado, en forma de galería porti-

\footnotetext{
${ }^{19}$ Mosaicos del Museo Arqueológico Jerónimo Molina de Jumilla (CME IV, n. 79, láms 31-33 y n. 83, lám. 86) mitad s.IV; Arcos de la Frontera (Cádiz; CME IV, n. 46, lám. 19) s.V.
}

cada. Estas áreas son frecuentes en la arquitectura de las grandes villas señoriales de la Antigüedad tardía, como la de Piazza Armerina o la de Puente de la Olmilla en la península Ibérica ${ }^{20}$. La superficie documentada hasta el momento es de $22 \mathrm{~m}$ de longitud x 5,4 $\mathrm{m}$ de ancho. $\mathrm{La}$ galería, que en su origen estuvo porticada con columnas de orden jónico, está enteramente pavimentada con mosaico, aunque con un diseño discontinuo, como es habitual en la decoración musiva de los grandes corredores ${ }^{21}$. Ambas alfombras están delimitadas conjuntamente por una cenefa exterior formada mediante un meandro de doble línea de esvásticas entrelazadas formando un meandro de "T" contrapuestas ${ }^{22}$. En los vértices se generan cuadrados decorados por cuadrados entretejidos. En el lateral norte se añade además una banda de enlace formada por una línea de roleos y hojas de hiedra. La primera de las alfombras, de forma rectangular y de mayor dimensión hasta el momento, presenta una decoración con composición ortogonal de cruces de scutae, composición conocida a partir del s. IV, dibujadas mediante trenza polícroma de dos cabos sin continuidad aparente, formando círculos, rombos y octógonos. En los lados de la alfombra se generan semicírculos, triángulos y semioctógonos, decorados en su interior por ornamentación vegetal, círculos entretejidos, esvásticas en remolino y motivos geométricos. Le sigue otra alfombra con una composición ortogonal de círculos entrelazados a través de cables de trenza ${ }^{23}$. En su interior se forman semioctógonos de cuatro lados cóncavos. Decoran estas figuras ornamentos vegetales, peltas, nudos de salomón, escamas y un ajedrezado en tres filas y trazado diagonal.

B6. Estanque-ninfeo: El último de los ambientes del ala norte es un estanque de planta rectangular que presenta unas dimensiones de $18,5 \mathrm{~m} \mathrm{x} 2,95 \mathrm{~m}$ con remate biabsidal. Su eje mayor está orientado en sentido NW$\mathrm{SE}$, como el resto de las estructuras de la villa. El espacio lo cierra un muro perimetral de mampuesto de opus incertum revestido de opus signinum, al igual que el pavimento. Los ángulos producidos por la intersección de los distintos planos en el interior de la estructura (esquinas del muro perimetral y el suelo) se rematan con un matacán de opus signinum de perfil curvo-convexo. Este tipo de estructura viene tradicionalmente interpre-

${ }^{20}$ En la Villa de la Olmilla este espacio es denominado "gran pórtico" (García Bueno 1994: 97, fig. 2, n. 13).

${ }^{21}$ Villa de Liédena (Navarra; CME VII, I, peristilo, fig. 4, lám. 4).

${ }^{22}$ Decoración marginal muy común y extendida en el mundo romano, sirvan como ejemplo el mosaico de Los Torrejones, Yecla (CME IV n. 67, lám. 26) mitad. s. IV.

${ }^{23}$ Mosaico de Écija, Museo Arqueológico (López Monteagudo 1998). 
tándose como ninfeo, una vez descartada la posibilidad de que se usara como cisterna, ya que no presenta restos de cubierta y que la profundidad es escasa para este uso.

El ninfeo se hallaba unido a la fontana del peristilo a través de conducciones hidráulicas internas que posibilitaban el aprovechamiento del líquido de un estanque a otro. La ubicación del ninfeo, en un plano topográficamente más bajo, facilitaba la pendiente y por tanto el abastecimiento procedente de la fontana a través del mosaico en rampa. En el punto central del muro medianero de la galería y el lateral sur del ninfeo se halla un surtidor flanqueado por dos pequeñas hornacinas, ubicadas de forma simétrica en el lado sur, que pueden ser interpretadas como nichos escultóricos.

El desagüe del estanque se sitúa en el lateral este, motivo por el que la pendiente del área del pavimento se inclina ligeramente unos centímetros hacia este lado. Además presenta dos esclusas para el drenaje rápido del agua, abiertas en su muro norte, aunque probablemente estas aperturas se realizan en un momento posterior, quizá en la fase de reaprovechamiento de la estructura para el regadío de los cultivos del entorno.

B7. Espacio B7: Se trata del espacio más septentrional de la villa y constituye probablemente su límite en la fachada norte. Lo conocemos sólo parcialmente. En este caso, los pavimentos se encuentran muy deteriorados, apreciándose restos de decoración geométrica con trenzado polícromo de dos cabos que traza octógonos decorados en su interior con motivos figurados. El único de los octógonos conservados porta en su interior una figura convencional de dos erotes alados en pie que portan guirnaldas, ofreciendo uno de ellos una cesta a su compañero. Estas escenas de erotes estantes enfrentados tienen su origen en el arte helenístico y son muy comunes en el repertorio musivo, presentando infinitas variantes ${ }^{24}$. Es sobre todo muy frecuente su representación acompañando a imágenes de contenido estacional, aludiendo normalmente a la primavera, con flores y guirnaldas ${ }^{25}$.

Con respecto a los indicadores cronológicos, parece que nos encontramos con un espacio que ha tenido dos funciones completamente distintas e incompatibles. En una primera fase, probablemente formaría parte de las estancias residenciales de la casa, exhibiendo una decoración musiva de rico repertorio iconográfico, junto al estanque biabsidal con sus juegos de agua y sus esculturas. En una segunda etapa, relacionado probablemente con la apertura de las esclusas al estan-

${ }^{24}$ Vid. Greifenhagen 1957 sobre el origen y el desarrollo del tema de los erotes.

${ }^{25}$ Mosaico de Cupidos II en Complutum (Fernández Galiano 1984: 189-197, fig. 11, láms. CII-CVI). que para permitir su desagüe inmediato, este espacio habría perdido su función original. A partir de entonces entra en un proceso de deterioro, acelerado por la nueva escorrentía que produce la esclusa y la falta de mantenimiento del pavimento. A este hecho hay que sumar la fragilidad de la cama que lo sustentaba, que poco tiene que ver con el grosor y la calidad del resto de los mosaicos ${ }^{26}$.

\section{Habitaciones y espacios del "ala oeste del peristilo"}

En este sector de la villa nos encontramos con una serie de estancias que, según los esquemas conocidos de implantación arquitectónica de domus y villae romanas suelen atribuirse a espacios relacionados con la recepción y al desenvolvimiento de las tareas públicas del dominus de la casa. La prestancia arquitectónica de estas salas parece reforzarse mediante el tipo de construcción, que añade a los habituales muros de opus incertum grandes sillares de arenisca en los ángulos y extremos de las estancias.

C1. Espacio C1: Estancia abierta al peristilo. Presenta unas dimensiones de 7,4 $\mathrm{m}$ x 5,5 m y está pavimentada por completo con un mosaico polícromo (fig. 4). Su acceso se encontraba enmarcado por dos columnas, cuyas basas de caliza marmórea "blanco Andalucía" se han conservado in situ. Su posición central en el peristilo, la entrada columnada a modo de oecus y el pavimento musivo, indican su carácter de sala de representación. El mosaico presenta una decoración de estrellas de ocho losanges formando cuadros rectos y otros sobre la punta, proporcionando un ejemplo más de esta extendidísima composición, que aparece desde el s.I a.C. en ejemplos muy lineales en blanco y negro y se enriquece progresivamente hasta aparecer en suelos como el antequerano, polícromos y profusamente decorados ${ }^{27}$, en este caso mediante cabos entretejidos y nudos de salomón. La orla está decorada mediante un abigarrado meandro de esvásticas con vuelta simple.

En el centro de la sala aparece sobre el mosaico una superficie de ladrillos de $1 \mathrm{~m}$ x 1,5 m que parece corresponder a un reaprovechamiento de la estancia, posiblemente con el objeto de situar un pilar que sirviera para la sujeción de la techumbre en un momento de amortización de la villa en el que la pesada cubierta amenazara con su derrumbe.

${ }^{26}$ Este hecho pudo confirmarse durante las obras de extracción y restauración de la pieza y ha quedado sobradamente documentado en la memoria de estos trabajos.

27 Villa Romana de Marbella (CME III, p. 83-84, n. 58, lám. 68 a) s. II-comienzos del III. Mosaico con busto de Baco de Itálica, Museo Arqueológico Provincial de Sevilla (CME I, p. 2627, n. 2, lám. 8-10) s. II. 


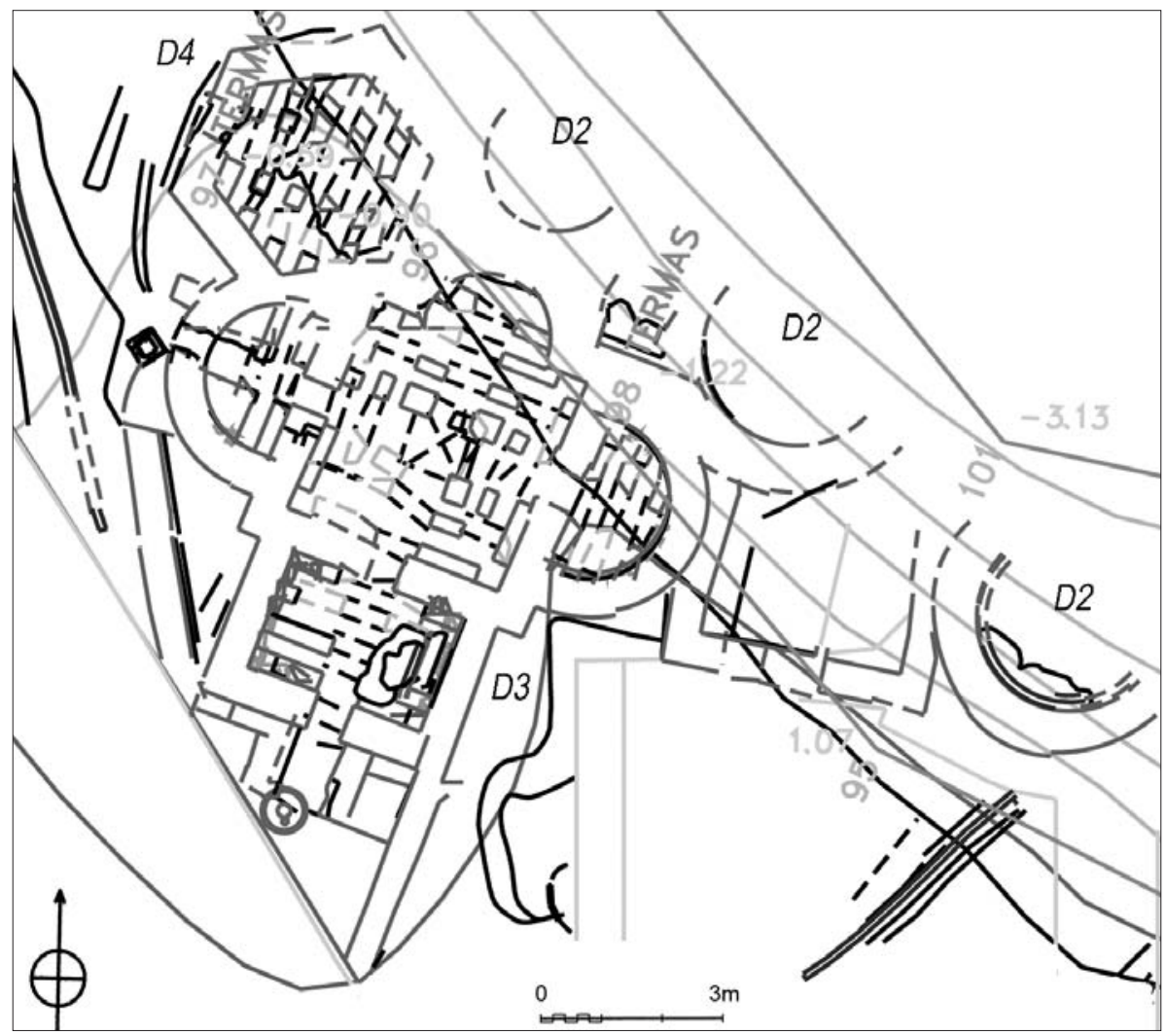

Figura 5. Planta general de las termas después de la intervención de 2005.

C2 . Espacio C2: La habitación, destruída parcialmente por la construcción de una zanja ${ }^{28}$, presenta planta alargada en forma de corredor con unas dimensiones de $26 \mathrm{~m}$ x 4,35 m y está rematada en exedra a modo de cabecera. Este tipo de estancias cuenta con numerosos paralelos en las grandes villas tardoimperiales ${ }^{29}$. El suelo aparece aterrazado en tres niveles y probablemente se encontrara pavimentado con mosaico en todo su

${ }^{28}$ Como incidencia más importante señalaremos la existencia de una zanja de unos 1,6 ms de ancho que recorre toda la habitación en sentido sur-norte, realizada en 1997 para la instalación del tubo colector de drenaje de la carretera de circunvalación. Fue realizada sin control arqueológico y desatendiendo las instrucciones dadas a la empresa constructora por parte de la Junta de Andalucía (Informe de las medidas correctoras de tipo arqueológico para la obra "Circunvalación Norte de Antequera. Delegación Provincial de Cultura).

${ }^{29}$ En la Villa romana de la Calle Primavera (Fresneda et alii 1991: fig. 1). Varias de estas estancias aparecen en las grandes villas de la meseta, como la de Cuevas de Soria (CME VI, n. 61, fig.10; n.62, fig. 11 ; n.63, fig. 12 ; n.65, fig. 14 ; n.66, fig. 15 ; n. 68 , fig. 17) desarrollo. El primero de ellos (exedra) apenas ha conservado restos de pavimentación, debido a la zanja mencionada. El segundo (central), aparece a una cota $0,55 \mathrm{~m}$ superior. Se trata de un espacio pavimentado con mosaico. La banda exterior, que delimita la alfombra, está decorada mediante un meandro de doble línea de esvásticas entrelazadas formando un meandro de "T" contrapuestas. En el interior alberga una composición de cuadros diagonales a los lados de la estancia, separados mediante un trenzado polícromo de dos cabos. Esta composición de cuadros, ortogonales u oblicuos, conocida de antiguo, experimenta una gran difusión durante el s.IV. Los 29 paneles albergan distintos motivos geométricos y vegetales, como ruedas de peltas, nudos de Salomón o círculos entretejidos. El repertorio decorativo coincide prácticamente con el de la estancia B5, pudiéndosele aplicar las mismas consideraciones cronológicas y de estilo. Entre ambas terrazas se han localizado los restos de una pequeña fuente de planta semicircular, empotrada en el muro oeste de la habitación.

Esta estancia continúa hacia el sur a través de dos escalones recubiertos de mármol que dan acceso a otro tramo en el que se puede apreciar restos de pavimenta- 


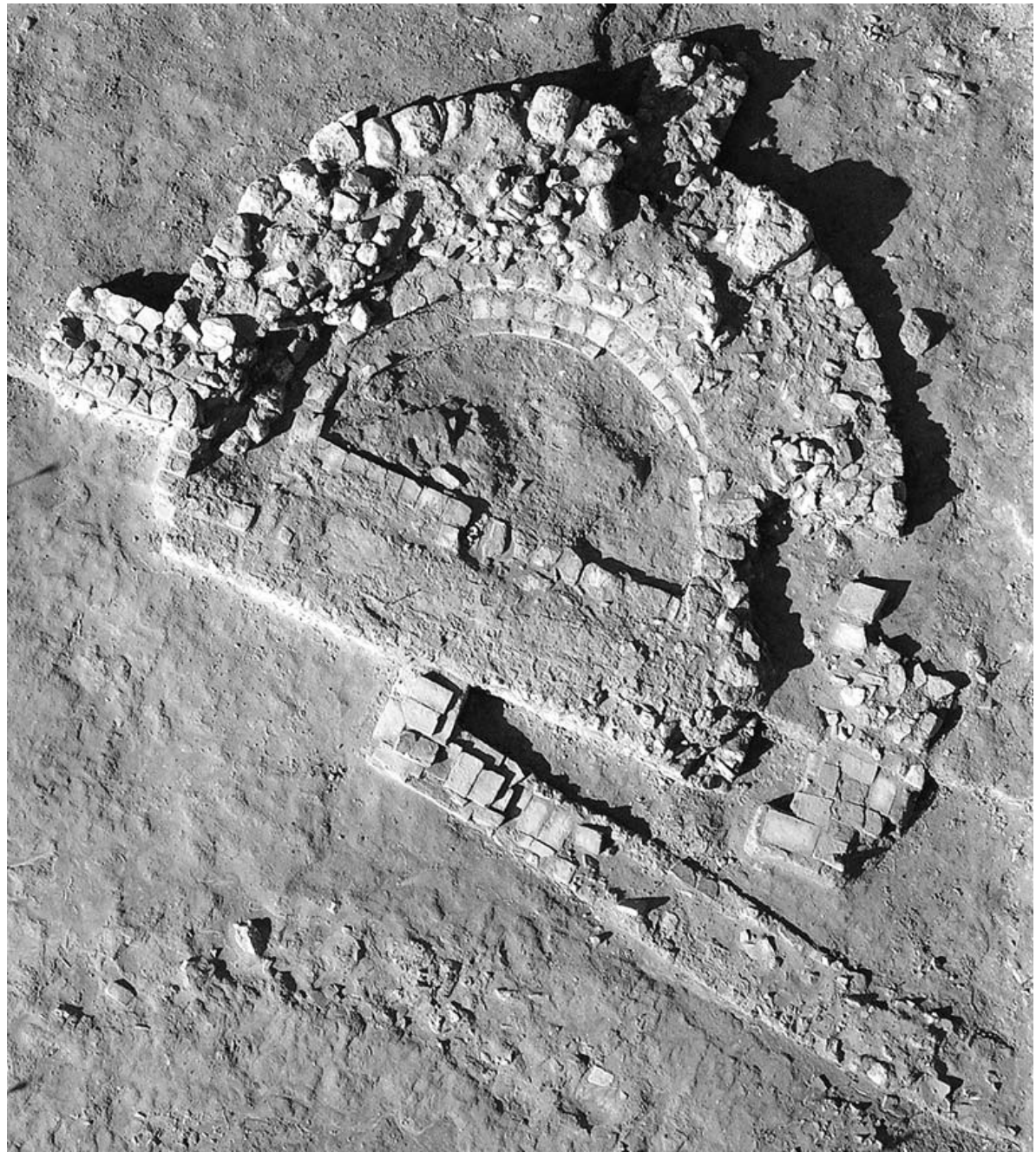

Figura 6. Fuente en exedra (D1).

ción musiva, con un motivo decorativo de esvásticas entrelazadas, pero que permanece oculta bajo el arcén de la actual N-331.

C3. Espacio C3: Espacio existente entre el muro oeste de cierre de la villa y la estancia anterior, marginal respecto de otras salas y sin trazas de pavimentación, por lo que cabe la posibilidad de que se trate de un espacio destinado al tránsito del personal doméstico o a estancias relacionadas con el servicio o la ventilación, sin que podamos ofrecer más datos hasta que no se complete su excavación.

Cerrando la villa por su lado oeste, se ha localizado un acceso monumental enmarcado por columnas que cierra el recinto y a la vez comunica este espacio residencial con sus termas, situadas en el sector noroeste. Esta gran puerta, que marca la transición entre ambos espacios, presenta planta absidada y se encuentra pavimentada con ladrillos. Las huellas donde se ubicaban los bornes de las hojas de la puerta permanecen in situ sobre un peldaño, realizado con varios sillares de arenisca que nos indican la apertura de ésta hacia el interior. En su cara sur quedan los restos de una torre cuadrada de $2,2 \mathrm{~m}$ de lado, unida a un muro de cierre que se conserva en una longitud de $21 \mathrm{~m}$.

\section{Las "termas" 30 .}

Las termas de la Villa de la Estación se disponen formando una identidad arquitectónica independiente y

\footnotetext{
${ }^{30}$ Los resultados que aquí presentamos tienen un carácter provisional, en tanto que las estructuras termales no están excavadas en su totalidad, buena parte de las mismas están soterradas bajo la actual N-331 y el sector norte fue seccionado literalmente por la construcción, a comienzos de siglo, de un camino de acceso al antiguo paso a nivel.
} 


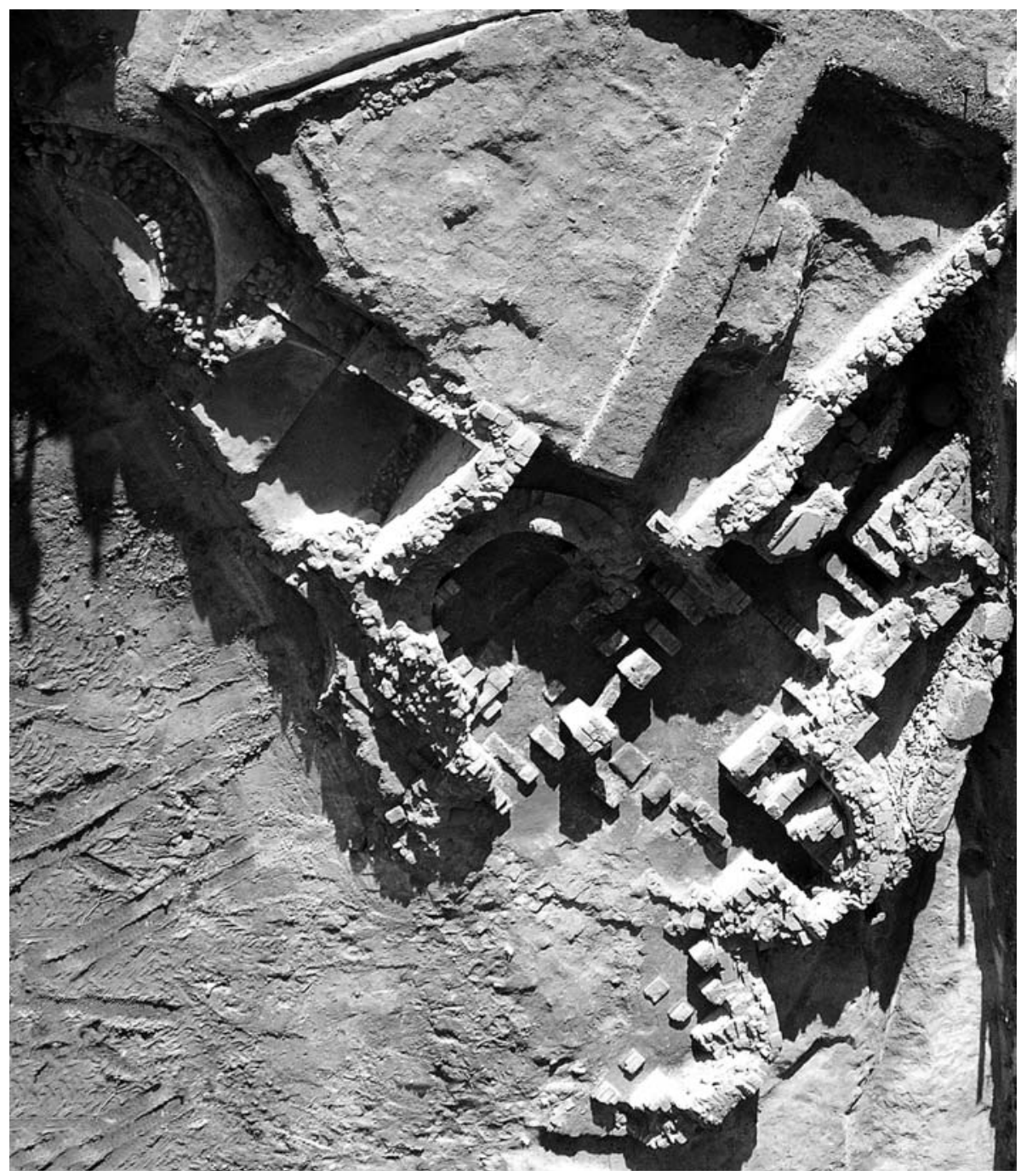

Figura 7. Restos de las termas.

en una ubicación recurrente (sector noroccidental) en gran parte de los balneae localizados en villas ${ }^{31}$. El espacio termal, donde prima la construccion latericia, constituye un complejo arquitectónico independiente dentro del conjunto de la villa (fig. 5), pero probablemente planificado de manera unitaria con el área residencial. Hasta el momento se han localizado tres piscinas de planta redonda y dos salas calefactadas de forma directa mediante sistema de hypocausta, un caldarium y un laconicum probablemente, trilobulado y de planta hexagonal respectivamente, además de una gran fuente

\footnotetext{
${ }^{31}$ Fernández Castro 1982: 102.
}

en exedra. A pesar de que la excavación del área ha sido sólo parcial, sin que sea todavía posible restituir el esquema de circulación de las termas, parece deducirse que las salas cálidas y frías se hallaban separadas, orientándose al poniente las cálidas, con el objetivo de preservar el calor hasta las últimas horas de la tarde, como recomienda Vitrubio (De Arch. VI4). A continuación describimos someramente las estructuras conservadas.

D1. Fuente en exedra: En eje con el acceso al complejo residencial más cercano a las termas y enfrentada a él, se hallan los restos de una fuente en exedra (fig. 6). De planta semicircular, cuenta con un diámetro máximo de 6,4 $\mathrm{m}$ de lado. Aparece contrafortada en sus extremos y en el centro. Presenta un suelo de 


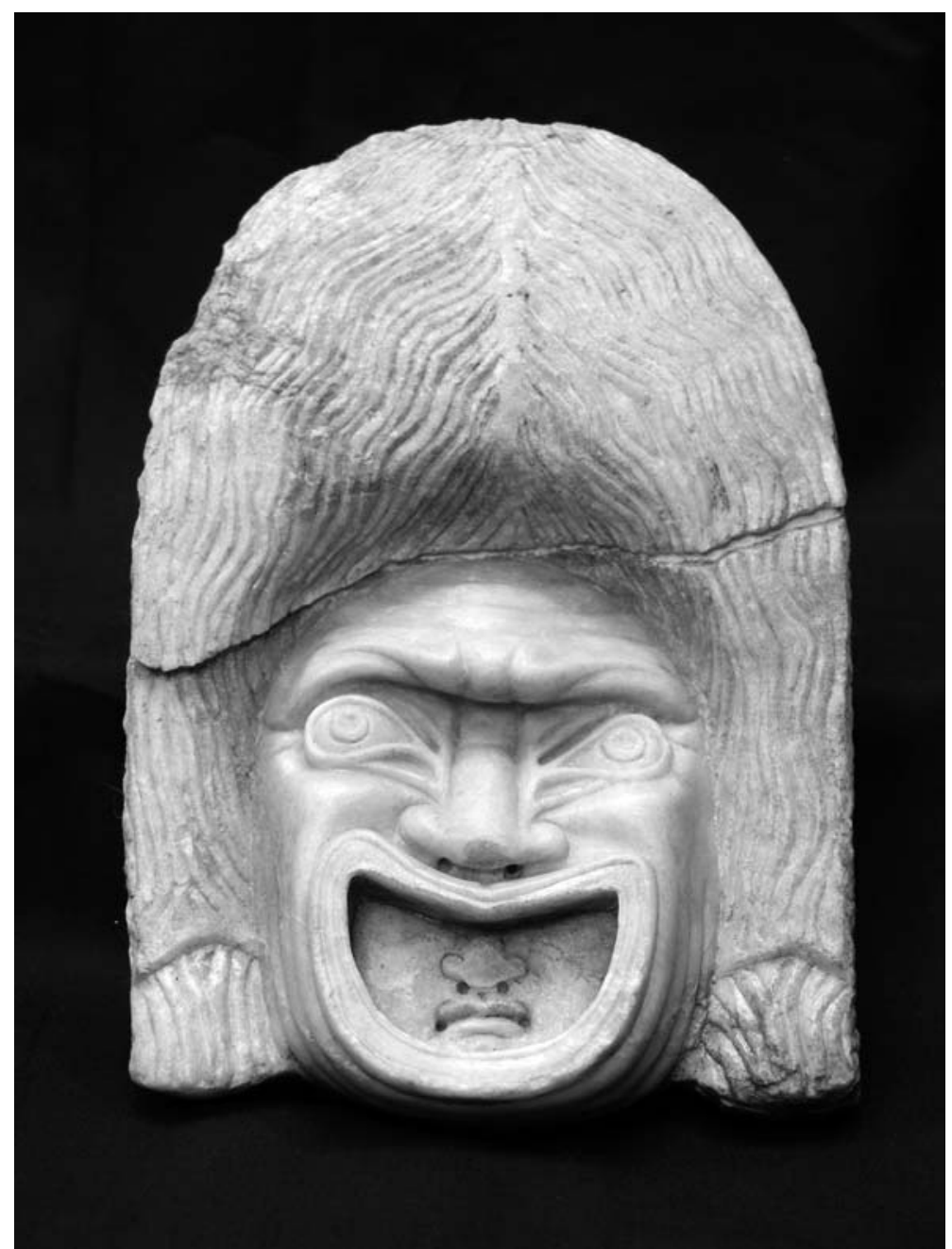

Figura 8. Antefija con actor y máscara trágica.

opus signinum con restos de incrustaciones de teselas de pasta vítrea, frecuentes en este tipo de construcciones relacionadas con usos acuáticos. En su eje central aparece un canal de desagüe cerrado, de ladrillo y mampuestos, que facilita el drenaje en dirección noreste, siguiendo la pendiente natural del terreno. Se trata de una fuente monumental exenta que se encuentra ubicada entre las termas y el espacio residencial.

D2. Piscinae: Se han localizado los restos de tres estructuras circulares no calefactadas y alineadas, de 3,2 m de diámetro cada una, con revestimiento impermeabilizante de opus signinum y matacán de media caña en la unión de las paredes con el pavimento. Parecen responder a la tipología de piscinae y pueden por tanto ser interpretadas como las piscinae del frigidarium, que se encuentra probablemente adosado o muy próximo a estas estructuras. Pueden citarse distintos paralelos de este tipo de estructuras, con tamaños muy variables ${ }^{32}$.

${ }^{32}$ Una interesante discusión acerca de las estancias termales de planta circular en Bouet 2003: 56-58, fig. 37. Un tamaño de 2,70 $\mathrm{m}$, semejante al antequerano en las termas de la domus de Place de la Haute-Vieille-Tour en Rouen (Francia), de inicios del s. III (Bouet 2003: 57). Estructuras circulares semejantes se encuentran en el balneario Oeste de la Villa de Milreu, Estoi, (Faro, Portugal) finales del siglo III d. C-inicios del IV d. C, o en el Balneario Oeste de Cerro Da Vila en Quarteira, Loulé (Faro, Portugal), donde la estructura circular funcionaba como frigidarium pudiendose datar, probablemente a comienzos del s. IV (Reis 2004: 118, fig. 56a). En España encontramos estructuras circulares adscritas a complejos termales en Munigua (Villanueva del Río y Minas, Sevilla) de mediados del siglo I d. C.; Campo Valdes (Gijón) siglos I-II d. C., o en las termas imperiales de Clunia fechadas en el siglo II d. C. (Fernández Ochoa et alii, 2000: 59-72). 
D3. Caldarium. Se trata de una gran sala desarrollada según el esquema trilobular frecuente en la Antigüedad tardía (fig. 7). La habitación oblonga se prolonga en una piscina de agua caliente, alveus, muy semejante a la de la Villa de la Olmeda ${ }^{33}$. Salas trilobuladas se encuentran en Mérida, en el Balneum de la casa de los Mármoles en el área arqueológica de Morería, que se ha interpretado como una bañera de agua fría (s. IV) ${ }^{34}$, o en la Villa romana del Camino Viejo de las Sepulturas (Balazote, Albacete) interpretado como caldarium o laconicum $^{35}$. El sistema de calefacción de esta sala se alimentaba a traves de dos praefurnia, uno principal en eje con el alveus central y otro, secundario y más pequeño, en el lado occidental, ambos de planta rectangular, con bóveda de acceso y sistemas de suspensurae de doble arco.

D4. Caldarium/laconicum de planta hexagonal. Esta estancia calefactada se encuentra situada al noreste de la anterior. Se ha conservado aproximadamente un $50 \%$ del total de la estructura de ladrillos. Tiene planta hexagonal, presentando cada uno de sus lados unas dimensiones de 1,9 m. La entrada del hypocaustum se situa en el lado oeste y se realiza mediante un arco de medio punto construido igualmente con ladrillos. En su interior se han conservado sólo tres de los pilares que sustentaban los arcos de las suspensurae. Este tipo de sala hexagonal la encontramos en la casa de Cantaber en Condeixa-a-Velha, Condeixa-a-Nova, (Coimbra, Portugal) ${ }^{36}$, donde aparecen dos salas de estas características que se han interpretado como tepidarium y como sudatorium y que forman parte de una importante remodelación que sufriría el conjunto termal a finales del siglo III d. C-principios del IV d. C. Planta hexagonal presenta también el espacio que se ha interpretado como un posible depósito en las termas de la villa de Torre da Cardería, Quintos (Beja, Portugal) fechadas, posiblemente, a mediados del siglo IV d.C ${ }^{37}$.

A pesar de la riqueza de la decoración musiva y escultórica de la villa, en el balneum no se han hallado restos ornamentales, a excepción de los restos de teselas de pasta vítrea halladas en la fuente en exedra.

\section{EL REPERTORIO ESCULTÓRICO}

En las excavaciones se ha localizado un nutrido grupo de esculturas que por su gran interés avanzamos aquí aunque de manera sucinta, por encontrarse aún en

\footnotetext{
${ }^{33}$ Nozal et alii 2000

${ }^{34}$ Reis 2004: 80.

${ }^{35}$ De los Santos Gallego 1977: 367-370.

${ }^{36}$ Reis 2004: 68-70.

37 Reis 2004: 94-95.
}

fase de estudio ${ }^{38}$. Se trata de varias esculturas de pequeño y mediano formato, datadas entre los siglos I y III, realizadas sobre distintos mármoles locales y de importación. El repertorio decorativo está constituido por representaciones con algunos temas característicos que forman las colecciones de la escultura doméstica roma$\mathrm{na}^{39}$, e incluye piezas con diferentes funciones. Fueron localizadas principalmente en el interior del estanque del peristilo, como si hubieran sido arrojadas a él, según una práctica que resulta frecuente en la Antigüedad tardía ${ }^{40}$.

Entre ellas se cuentan dos antefijas con moldura trasera que comparten motivos teatrales, por lo que podemos suponer la existencia de un programa iconográfico referente al teatro que ornara el entablamento del peristilo.

La primera de ellas es una máscara teatral ${ }^{41}$, atributo de la musa de la tragedia griega Melpómene ${ }^{42}$. Ofrece una cara estilizada de patética expresión, mentón pronunciado y boca exageradamente abierta, en doloroso gesto. Los ojos almendrados recuerdan sorprendentemente los tipos arcaicos helenísticos, pero con la pupila, el iris y los párpados perfectamente marcados. Lleva un peinado elevado (onkos) que cae como bloque de tirabuzones carentes de movimiento simétricamente a ambos lados de la cara ${ }^{43}$.

La otra antefija (fig. 8) representa un actor con máscara trágica tocada con onkos ${ }^{44}$. Esta expresiva máscara difiere profundamente de la rigidez arcaizante de la anterior. La peluca es alta, compuesta por una serie de tirabuzones que caen en cascada sobre la frente y a ambos lados del rostro, hasta el mentón. El tipo de peinado responde a la moda de las máscaras utilizadas en las tragedias de la época imperial. La expresión de terror se consigue a través de la mirada y del ceño fruncido. La boca, grande y abierta, deja asomar desde su interior el rostro del actor (nariz, pómulos y labios) que tras ella se esconde ${ }^{45}$.

38 Vid. también el primer estudio de algunas de estas piezas que realizó el Dr. Rodríguez Oliva (Rodríguez Oliva 2004: 5257). Queremos agradecer a los Dres. Rodríguez Oliva y Loza Azuaga la ayuda prestada en el estudio del repertorio escultórico.

39 Koppel 1995.

40 Vaquerizo 1990: 144.

41 VE.98.H8.1-26. Mármol blanco de grano fino. 17 x 10,5 x 13 cm. s.II d.C. (Rodríguez Oliva 2004: 54, fig. 10).

${ }^{42}$ Sobre el significado de las representaciones de Melpómene y su uso en ambientes privados (Rodríguez Oliva 1993).

${ }^{43}$ Paralelos a estos peinados existen en los relieves con máscaras de Pompeya (Dweyer 1982: lam. XXVIII, fig. 106; lam. XIX, figs. 109, 110).

${ }^{44}$ VE.05.E3-UE002-006. Mármol blanco con veteado gris de grano fino. $23 \times 15 \times 6 \mathrm{~cm}$. s. II d.C.

${ }^{45}$ Un paralelo, aunque notablemente más esquemático, en el Museo Arqueológico de Barcelona. (Rodríguez Oliva 1993: 62, lam. X, 1-2). 

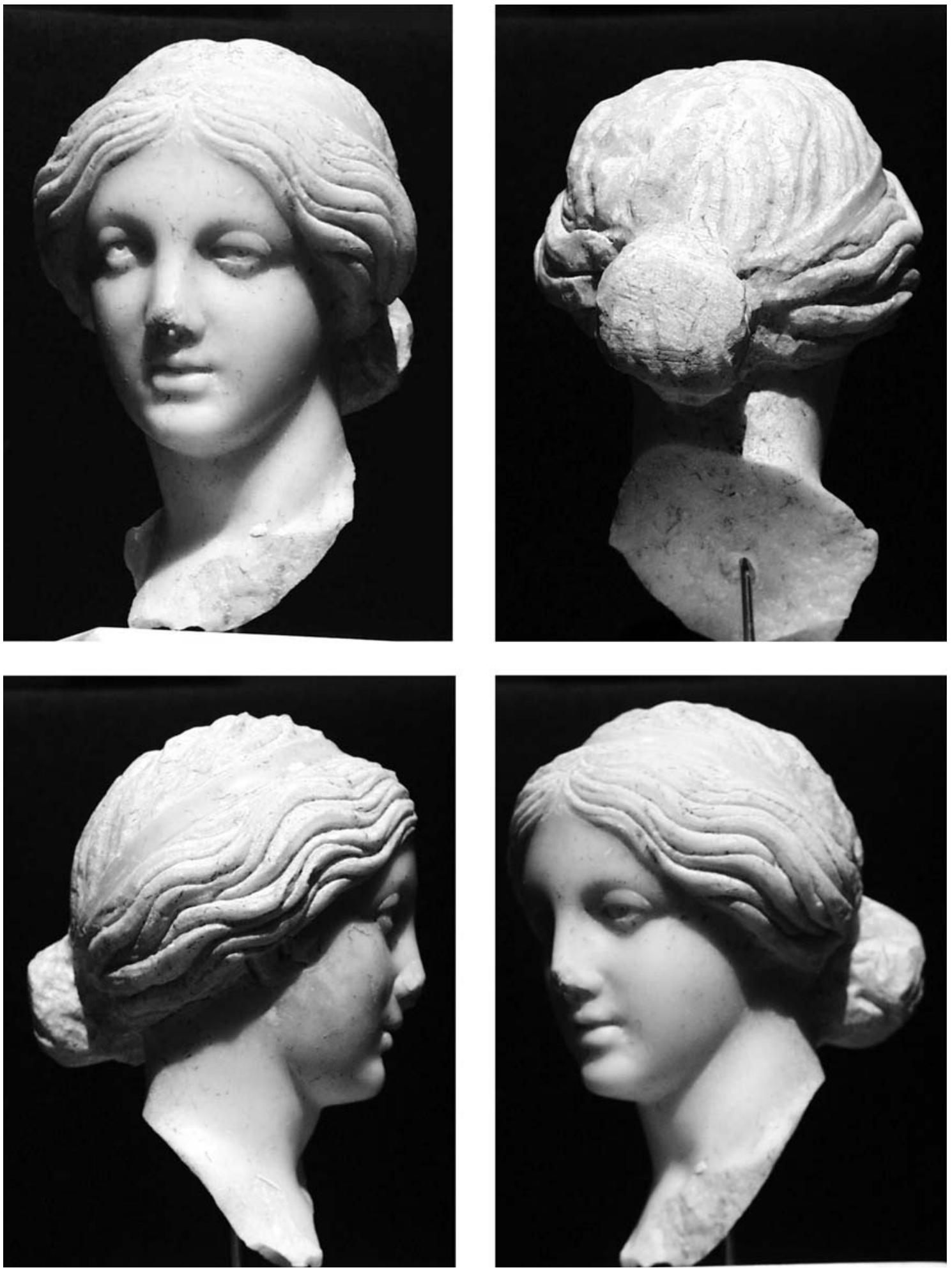

Figura 9. Cabeza ideal femenina. 


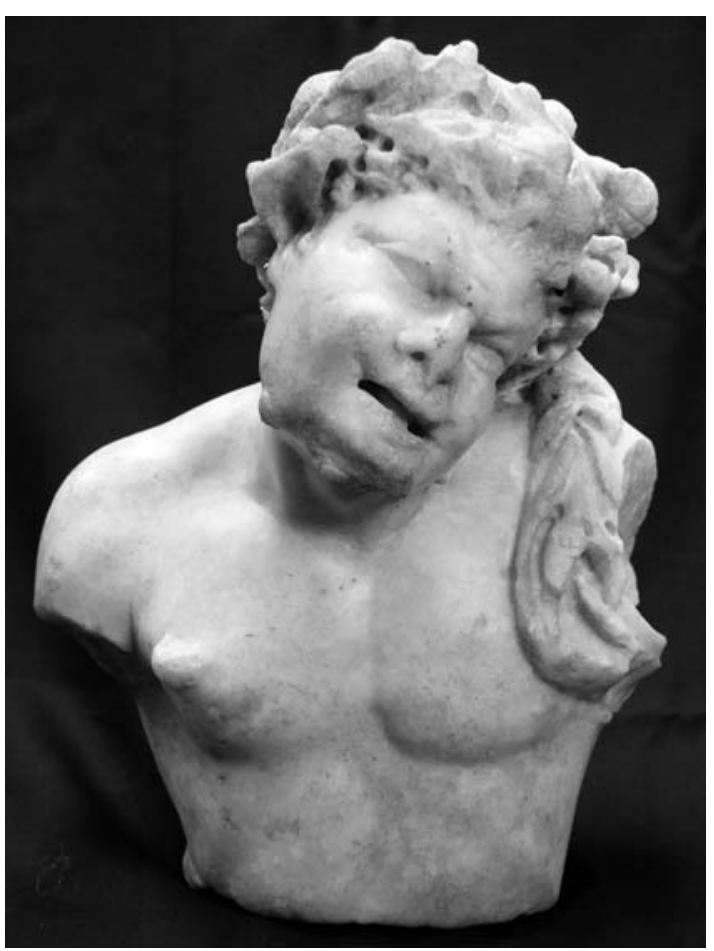

Figura 10. Fragmento de estatua-fuente de Sátiro.

Otra de las destacadas esculturas representa un Eros-Hypnos infantil ${ }^{46}$. Se conserva parte de la peana y el cuerpo del erote durmiente, desde la cabeza hasta la cintura, con una longitud de apenas $30 \mathrm{~cm}$. La figura, recostada, tiene sus alas plegadas y la cabeza que reposa blandamente sobre su hombro izquierdo, con los ojos cerrados y la boca entreabierta. Con laxitud tiene en su mano izquierda un manojo de adormideras, mientras que con la mano derecha parece sujetar parte de un arco, lo que lo ubicaría dentro de la serie bien conocida de representaciones escultóricas en las que ErosHypnos adopta algunos atributos de Hércules ${ }^{47}$. El uso de este motivo como ornamento de ámbitos con presencia de agua, como termas, peristilos y jardines de las villas, está bien documentado en Hispania y en concre-

46 VE.98.E.1-364. Mármol blanco de grano fino. 17 x 10,5 x $4,2 \mathrm{~cm}$. Finales del s. II $-1^{\mathrm{a}}$ mitad del s. III d.C. (Rodríguez Oliva 2004: 56, fig. 12).

47 Otras representaciones de Eros-Hypnos en la península: Eros-Hypnos de la Villa de Algorós en Elche (Arasa I Gil 2002: 238-239, figs. 1-2; García y Bellido 1949: n. 113, lám. 88); Cabra (Jiménez Salvador y Martín-Bueno 1992: 70); Tiermes (García y Bellido 1949: n. 114, lám. 89); Colección Monsalud (Extremadura; García y Bellido 1949: n. 113, lám. 89); Elvas (Portugal; García y Bellido 1949: n. 115, lám. 89). to en la Bética (Cabra) ${ }^{48}$, donde la misma figura es un surtidor.

También se ha recuperado una cabeza ideal femenina ${ }^{49}$ que probablemente perteneciera a una escultura de cuerpo entero (fig. 9). Ya en otras sedes se ha propuesto una posible identificación con Venus ${ }^{50}$, aunque no podríamos tampoco descartar que se tratase de otra divinidad, una Musa o una Ninfa. La posición es frontal, aunque el rostro, de facciones llenas, juveniles y sumamente idealizadas, se vuelve levemente hacia el lado izquierdo. Los ojos son de corte almendrado-redondeado, el iris y la pupila aparecen definidos mediante rehundimiento. La carnosa boca, de labios pequeños, está entreabierta. Los cabellos se ordenan mediante raya central. La melena se articula en dos voluminosos aladares, con mechones delineados mediante trazos ondulados que ocultan las orejas y convergen en la nuca, junto al resto del pelo, en un moño trabajado con descuido por el escultor. Contrasta con la talla delicada de la cinta que ciñe sus cabellos, dibujando un casquete hemisférico en la caja craneal donde se vuelve a perder el detalle de los mechones.

Igualmente han sido hallados varios fragmentos escultóricos pertenecientes al mundo del thyasos dionisiaco, que gozó de un gran predicamento en la escultura de los contextos domésticos en el mundo romano ${ }^{51}$.

El primero de ellos (fig. 10) remite a un conocido prototipo en el que un sátiro aparece sentado sobre una roca, en actitud de tocar muy probablemente un instrumento musical con la mano derecha y de sostener un ánfora con la izquierda ${ }^{52}$. El ejemplar es prácticamente idéntico a dos piezas procedentes de Itálica y Arcos de la Frontera ${ }^{53}$ y todos retoman un conocido original tardohelenístico. El uso del motivo como estatua-fuente está documentado en otros ambientes domésticos de Hispania ${ }^{54}$.

El segundo, en estado muy fragmentario, representa el abdomen y extremidades inferiores desnudas de un

48 Jiménez Salvador; Martín-Bueno 1992: 69-70.

49 VE.01.E.2-71. Mármol blanco de grano fino. 17 x 12 x $13 \mathrm{~cm}$. S.II? (Rodríguez Oliva 2004: 53, fig. 14).

${ }^{50}$ Cabezas ideales femeninas de inspiración semejante en el Museo Arqueológico de Málaga (Baena 1984: 49-54) n. 6, lám. 7) y en la Quinta das Longas (Nogales, Carvalho, Almeida 2004: 134, fig. 16).

51 Sobre el papel ornamental de estos temas en domus y villae vid. Vaquerizo y Noguera 1997: 124.

${ }^{52}$ VE.05.E18-UE003-17. Mármol blanco de grano fino. 28 x $22 \times 11 \mathrm{~cm}$. Segundo cuarto del s. I d.C.

${ }^{53}$ León 1995: 160, n. 53; Hispania Antiqua 1993: 388, lám. $186 b$.

${ }^{54}$ León 1995: 160, n. 53 que remite para el prototipo al trabajo de Wrede (Wrede 1986) y a la tesis de M. L. Loza La decoración escultórica de fuentes en Hispania. Universidad de Málaga. 
sátiro de gran calidad y belleza ${ }^{55}$. Se conserva la parte superior de los muslos hasta la altura de la cintura. Presenta en su frontal el falo y bien marcado el vello púbico. En el reverso se dibujan los glúteos redondeados y un pequeño apéndice o cola que lo identifica como sátiro $^{56}$.

El último de ellos es también una pequeña cabecita de sátiro ${ }^{57}$. Las facciones de la cara se reproducen con esmero e identifican claramente una iconografía infantil. Los pómulos redondeados y carnosos así lo demuestran, al tiempo que se intensifica la carga expresiva con la satírica sonrisa que permite entrever los dientes. El tratamiento del cabello, hirsuto y dividido en tres campos, deja a la vista un característico atributo del personaje: las orejas puntiagudas caprinas ${ }^{58}$.

En el centro de una de las cuatro tazas del estanque apareció otra escultura-fuente: se trata de una representación con una figura desnuda, posiblemente un amorcillo o erote, que cabalga sobre un animal marino ${ }^{59}$ (un delfín con cabalgadura o un animal acuático imaginario). La boca del animal presenta una apertura para la tubería de plomo surtidora de agua. Se trata de un motivo bien conocido en el mundo romano, derivado de notables creaciones tardoclásicas y helenísticas y reproducido sobre todo en pequeños formatos ${ }^{60}$.

También destinado a servir como ornamento de fuente encontramos la figurilla de un hipopótamo ${ }^{61}$. Éste presenta un orificio para el agua que va desde la pata delantera izquierda hasta la parte inferior del ojo izquierdo. La factura es muy irregular, con detalles en el cuello, lomo y en la cabeza y descuidada en el resto. Esta representación fue probablemente elegida adecuándose a la moda egiptizante romana que siempre vinculó

55 VE.98.H3.1M-34. Mármol blanco de grano fino. 19 x 12 x 8 cm. S. I d.C. $-1^{\text {a }}$ mitad del s. II d.C. (Rodríguez Oliva 2004: 54, fig. 13).

${ }^{56}$ Un paralelo de iconografía muy semejante, aunque de factura menos elegante, en fue hallada en el Valle de Abdalaxis, muy cercano a Antequera (Rodríguez de Berlanga 1903, 176: n. 40 y 98-99, lám. VII).

57 VE.05.E.2-72. Mármol blanco de grano fino y compacto. $9 \times 6,5 \times 5 \mathrm{~cm}$. Finales del s. II d.C.

${ }^{58}$ Guarda una gran semejanza con una obra hallada en Tarragona, probablemente también una escultura de jardín del s. II d.C. (García y Bellido 1949: n. 93, lám. 78).

59 VE.98.EC.2 ${ }^{\circ} .1-1$. Mármol blanco de grano fino. 41 x 25 , apoyado en un pedestal de $27 \times 15 \mathrm{~cm}$. Finales del s. II $-1^{\mathrm{a}}$ mitad del s. III d.C. (Rodríguez Oliva 2004: 54, fig. 11).

${ }^{60}$ Un paralelo también sobre pedestal que ornaba además el centro de una fuente en las excavaciones de Pietra Papa en Roma (Jacopi 1943: 44, fig. 48). Otros ejemplos de esta tipología en la obra de Kapossy (Kapossy 1969: 38-39).

${ }^{61}$ VE.05 .E5 002-019. Mármol blanco de grano fino. $19 \mathrm{~cm}$ x $15 \mathrm{~cm}$. s. II d.C. a este exótico animal con contextos acuáticos que evocaban los paisajes nilóticos ${ }^{62}$.

Junto a la puerta de acceso a las termas de la villa se ha hallado un relieve en forma de disco con retrato masculino ${ }^{63}$. Éste presenta un peinado corto, pegado al cráneo, delimitados los mechones mediante golpes de cincel, en un estilo propio de la retratística del siglo III d.C. Las entradas del cabello están bien acentuadas y dejan al descubierto una frente abundante y redondeada; asimismo lleva una barba de mediano desarrollo. Los labios son prominentes y la nariz rectilínea. Los ojos tienen el iris y la pupila bien marcados. Podría tratarse de la imagen de un filósofo, aunque puede también sugerirse su identificación con un clípeo de mármol que siguiendo la tradición romana represente al propietario de la villa, como muestran algunas pinturas pompeyanas ${ }^{64}$. El hallazgo de la pieza en el nivel de derrumbe que amortizaba el flanco sur de la citada puerta parecería indicar que se encontraba situada siguiendo un patrón de ubicación de tradición netamente republicana, que colocaba estos retratos junto a las puertas. Se trata, por cuanto conocemos, del primer hallazgo de una imago clipeata in situ en la península Ibérica.

\section{LA EVIDENCIA CRONOLÓGICA ${ }^{65}$}

En lo que se refiere a la vida del conjunto en los momentos anteriores a la fase arquitectónica de la villa que hoy contemplamos, los resultados son aún extremadamente provisionales ${ }^{66}$. A la espera de realizar los sondeos proyectados bajo los pavimentos musivos, que indiquen más precisos hitos post quem, debemos señalar la ausencia de un contexto estratigráfico claro para los materiales anteriores al s. III d.C.

${ }^{62}$ Como es el caso de los distintos mosaicos nilóticos. Dos esculturas en pequeño y mediano formato en la NY Carlsberg Gliptothek (Copenhage) y en el depósito dei Garibaldini (Roma) vid. fichas respectivas de John Ludd y Silvia Fabricio (de Nuccio, Ungaro 2002: 361-365).

63 VE.98.H13.1-9 Mármol blanco de grano fino. 19 x 19 x $3,5 \mathrm{~cm}$. A la espera del estudio definitivo, sus características iconográficas sugieren una cronología del 235 al 285 d.C.

${ }^{64}$ Casa dei Vetii (Pompeya VI, 15, 1).

${ }^{65}$ Hasta el momento se han hallado 19 monedas. De estas, 2 ejemplares pueden atribuirse a los s. I a.C y II d.C respectivamente. El resto pertenecen al s. IV. El repertorio numismático ha sido estudiado monográficamente (Melero García y Romero Pérez 2001). El n. ${ }^{\circ}$ total de fragmentos cerámicos exhumados es de 27.716, inventariados en 3.848 registros informatizados.

${ }^{66}$ Nos consta la presencia de habitación en las inmediaciones del emplazamiento de la villa desde el Bronce Final. Las cerámicas, muy rodadas, atribuíbles a este horizonte (18 fragmentos) posiblemente procedan del dominante cerro del Parador. 
Estos materiales, muy abundantes, se han exhumado exclusivamente en aquellos espacios donde fue posible establecer registros estratigráficos en niveles de subsuelo: Así, en la habitación C3, que carecía de pavimentación, se llevó a cabo un sondeo que proporcionó un cuadrante de Malaca (s.I a.C), cerámicas de tradición indígena e importada (campaniense, ática) y romana. El grueso de los materiales recuperados en estos sondeos realizados a nivel de subsuelo nos remite a época Flavia. En ellos se han identificado 42 fragmentos correspondientes a producciones de sigillata gálica y 120 de sigillata hispánica. Igualmente aparece gran cantidad de punzones de los talleres de Antikaria ${ }^{67}$ y de Singilia $\operatorname{Barba}^{68}$ (ss I-II d.C).

Un sestercio de Marco Aurelio fue encontrado igualmente en una cata realizada al exterior del denominado Espacio B4 o mosaico en rampa, con el objetivo de hallar un posible pavimento, con resultado negativo. Sin embargo esta moneda de finales del siglo II d. C., hallada en niveles de subsuelo, bien pudiera arrojar luz sobre una fecha ante quem de las últimas fases o remodelaciones de la villa.

Más evidente se muestra el registro arqueológico para fases más tardías (ss. IV-VI), especialmente representadas en todo el yacimiento. Existe un predominio de la formas de sigillata africana, en especial del tipo D, fósil guía que consideramos fiable para la datación de los niveles de uso y abandono de la villa.

De un total de 208 fragmentos de borde con información tipológica, son 187 los correspondientes a esta producción del tipo D. Más del $35 \%$ puede adscribirse a una horquilla temporal que oscila entre los s. IV y V (Lamboglia 54 / Hayes 61 y Lamboglia 38 / Hayes 91).

El $60 \%$ restante está formado por materiales manufacturados a lo largo de la segunda mitad del siglo $\mathrm{V}$ y del siglo VI, que perduran en algunos casos hasta principios del VII (Lamboglia 55B / Hayes 88; Hayes 90; Hayes 92; Hayes 99; Atlante 46,1; Hayes 103; Hayes 103-106; Hayes 104; Hayes 106; Hayes 107; Hayes 09 y Hayes 110). También se asocian con estas producciones 3 ejemplares de lucernas africanas del tipo Atlante Forma X, tipo A2 (s.V-VI) ${ }^{69}$. La dispersión espacial de estos materiales, regular y abundante en la mayoría de los espacios de la villa y las termas, nos inducen a considerar el s. VI como la datación más probable para el abandono del establecimiento, aunque somos conscientes de que el proceso de desocupación de una villa de estas dimensiones y con una localización tan próxima a la ciudad fue un proceso que tuvo que dilatarse mucho en el tiempo, lo que favorecería la reutilización funcio-

\footnotetext{
${ }^{67}$ Atencia Páez y Serrano Ramos 1999.

${ }^{68}$ Serrano Ramos 1991.

69 Anselmino 1981: 207
}

nal de las estancias, las reparaciones improvisadas y el expolio.

Los tipos A y C de la sigillata africana se encuentran también representados, aunque en cantidades muy inferiores $^{70}$. Las producciones de T.S.H.T.M (Terra Sigillata Hispánica Tardía Meridional) están presentes con 16 fragmentos de borde. Salvo un ejemplar, el resto puede encuadrarse cronológicamente en el siglo $\mathrm{V}$ d.C.

Con respecto al registro numismático, hay que constatar la inexistencia de moneda del siglo III d. C., que pudiera deberse al declive de aprovisionamiento general y que cambiará en la centuria siguiente. En el s. IV cabe destacar la distribución general de los hallazgos a lo largo de toda la centuria, así como su localización a través de toda la superficie del yacimiento. En principio se puede resaltar una evidente sintonía con el aumento general de circulación monetaria en el imperio durante dicha centuria. En el yacimiento hay constancia de acunaciones de las primeras seis décadas del siglo. La ausencia de tipos en el periodo 360 - 378 d. C. puede ser ocasional, o efecto no tanto de la disminución de la circulación de estos tipos en el territorio, sino del aumento general del AE 2 del periodo 378 - 395, que se aprecia bien en el registro de la villa. Con respecto a los últimos momentos, la presencia de un AE 2 de Honorio, que podría haberse acuñado entre 395 y 423 d. C., corrobora los planteamientos observados en el estudio de los materiales cerámicos respecto a las fases de ocupación tardías del edificio (siglos V y VI).

Todos los indicios apuntan que las estructuras excavadas hasta el momento se amortizaron mediante aportes sucesivos y rápidos de materiales procedentes del desmantelamiento de las estructuras, pensamos que por efecto de la ruina natural de las edificaciones tras su abandono. Hasta finales del siglo XVIII no se constata una intencionalidad manifiesta en los procesos de colmatación de las mismas, con la construcción de una era.

\section{CONCLUSIONES}

Aun siendo conscientes de la parcialidad de los datos, podemos avanzar algunas conclusiones de carácter provisional.

Resulta complejo ofrecer una datación fiable para la fundación de la villa, aunque los sondeos realizados en algunos puntos bajo los niveles de habitación de los

${ }^{70}$ Producción A. 13 fragmentos de la Lamboglia 3b1 / Hayes 14 B y Lamb.8 / Hayes 17, seguidas de 2 ejemplares de Lamb.41 / Hayes 33, en ámbitos cronológicos del s. III d.C. Las producciones de la variante C (4 ejemplares) oscilan entre el 350 d.C. de la forma Lamboglia 40 / Hayes 50 hasta el 475 d.C que presenta la 57 de Lamb./ Hayes 73. 
siglos III y IV d.C. proporcionan en muchos casos abundante material de la primera centuria ${ }^{71}$. Sin embargo de estas fases de habitación anteriores a finales del s. III o inicios del s. IV, momento en el que el análisis estilístico permite datar los mosaicos, no conocemos aún nada. En relación con la vida posterior del conjunto, es evidente que la continuidad y dispersión del material numismático y cerámico, así como la existencia de reparaciones en los mosaicos y de modificaciones en la estructura arquitectónica son testimonio de la pervivencia del hábitat con idéntica función (residencia señorial) hasta la primera mitad del s. VI, cuando posiblemente se produce su abandono y que daría paso al posterior expolio parcial de algunos de los muros.

A través de la planimetría conservada y a pesar de no conocerse más que parcialmente, parece claro que la Villa de la Estación, en la formulación arquitectónica que conocemos, respeta el principio de axialidad clásico de la arquitectura doméstica romana. Por otra parte, la notable conservación de la arquitectura y de la decoración permite establecer varios ambientes, diferenciándose en este sentido los espacios de carácter privado o semiprivado $^{72}$ de los espacios de recepción y representación del dominus.

En la decoración musiva se utilizan toda una serie de figuras geométricas y vegetales presentes en las producciones peninsulares anteriores, pero que por la selección y concentración de determinados motivos geométricos y su desarrollo estilístico recargado pueden fecharse principalmente a finales del s. III y en la primera mitad del s. IV, fecha que coincide con la obtenida a partir del estudio y análisis de otros materiales aparecidos en el transcurso de las excavaciones. Los mosaicos de la Villa de la Estación comparten con otros de la misma cronología idéntico lenguaje en la sintaxis geométrica, enriquecida con motivos decorativos ya muy fosilizados de atávico carácter benefactor (nudos de salomón, cráteras, cruces gamadas, hederae).

Por otra parte, el nivel de vida elevado y las aspiraciones de sus habitantes se perciben claramente en la villa, siendo un claro ejemplo del mismo la decoración de superficies que presenta, o la valiosa colección escul-

\footnotetext{
${ }^{71}$ Datos provisionales la espera de los sondeos estratigráficos que serán realizados bajo los pavimentos musivos. Otras villas en la Bética con desarrollos en los ss. III y IV tienen sus primeras fases en el s.I d.C. Villa del Ruedo (Vaquerizo y Noguera 1997:-35-36); Cabra (Jiménez Salvador y Martín Bueno 1992: 75-76).

${ }^{72}$ A pesar de que los estudiosos del ámbito doméstico señalan que no puede establecerse una dicotomía rígida público-privado en la casa romana, sí parece advertirse en la arquitectura un desarrollo progresivo de la voluntad de privacidad, que se manifiesta en la concentración y cierta separación del núcleo privado (Dunbabin 1994) así como en la generalización de los balneae.
}

tórica encontrada en las excavaciones. Esta colección contó con piezas de diferentes calidades y estuvo formada además por esculturas realizadas en varias épocas. Su destino era principalmente el ornamento del peristilo y su estanque central. La escultura recuerda por su inspiración conjuntos con modelos de cuño helenísticoromano tan importantes como los de la Villa romana da Quinta das Longas (Elvas), la de Valdetorres del Jarama (Madrid) o la del Ruedo de Almedinilla (Córdoba) ${ }^{73}$, que dan fe del lujo y la ostentación de las que hicieron gala sus propietarios. Incluso debe señalarse la presencia de algunos temas de carácter culto $^{74}$ bastante excepcionales en el panorama peninsular, como las antefijas con la máscara de Melpómene o con máscara y actor, o como el retrato de un filósofo, poeta-dramaturgo o propietario de la casa en forma de imago clipeata. Finalmente, la abundante presencia de agua en la villa y su barroca imbricación en el edificio y en su ambientación, parece evocar una refinada escenografía construida para albergar un concreto concepto de otium. De todos estos aspectos se trasluce la admiración por la cultura helenística y su potencial simbólico como modo de afirmación del carácter aristocrático de sus moradores.

\section{BIBLIOGRAFÍA}

ÁLVAREZ MARTÍNEZ, J. M. y NOGALES, T. (19941995), "Los mosaicos de la villa romana de Panes Perdidos. Solana de los Barros (Badajoz)", Anas 78, pp. 89-106.

ANSELMINO, L. (1981), "Terra sigillata: Lucerne" Atlante delle Forme Ceramiche I. EAA. Roma, pp. 184-207.

ARASA I GIL, F. (2004), "La decoración escultórica de las villae en el País Valenciano", en NOGALES BASARRATE T. y GONÇALVES L.J., Actas de la IV Reunión sobre Escultura Romana en Hispania. Madrid, pp. 229-256.

ATENCIA PÁEZ, R. (1979), Antikaria, ciudad romana. Memoria de licenciatura. Inédita. Universidad de Málaga. Málaga.

ATENCIA PÁEZ, R. y SERRANO RAMOS, E. (1980), "Las comunicaciones de Antequera en época romana”, Jábega 3, pp. 15-20.

ATENCIA PÁEZ,R. y SERRANO RAMOS, E. (1999), "El taller antikariense de terra sigillata hispánica". Figlinae Malacitanae, pp. 177-215.

\footnotetext{
73 Nogales, Carvalho y Almeida 2004; Vaquerizo 1990; Vaquerizo y Noguera 1997; Puerta, Elvira y Artigas 1994.

${ }^{74}$ Seguimos la designación propuesta por Koppel (Koppel 1995: 38) que señala la escasez general de este tipo de temas en Hispania.
} 
BAENA, L. (1984), Catálogo de esculturas del Museo de Málaga. Málaga.

BALMELLE, C. (2001), Les demeures aristocratiques d'Aquitaine. Société et culture de l'Antiquité tardive dans le Sud-Oest de la Gaule. París.

BOTO GONZÁLEZ, M. a y RINONES CARRANZA, A. (1989-90), "Villa romana de Auta. Riogordo (Málaga)" Mainake XI-XII, pp. 111-124.

BOUET, A. (2003). Les thermes privés et publics en Gaule Narbonnaise. Vols. I, II. Roma.

BLÁZQUEZ MARTÍNEZ, J.M., LÓPEZ MONTEAGUDO, G., SAN NICOLÁS, P. y NEIRA, L. (1987), "Mosaico romano de Vilches (Jaén)" AEA 155-156, pp. 275-280.

CABALLOS RUFINO, A., MARÍN FATUARTE, J. y RODRÍGUEZ HIDALGO, J.M. (1999), Itálica Arqueológica. Sevilla.

CME I. BLANCO FREIJEIRO, A. (1978), Mosaicos romanos de Mérida. Madrid.

CME II. BLANCO FREIJEIRO, A. (1978), Mosaicos romanos de Itálica (I). Madrid.

CME III. BLÁZQUEZ, J.M. (1982), Mosaicos romanos de Córdoba, Jaén y Málaga. Madrid.

CME IV. BLÁZQUEZ, J.M. (1981), Mosaicos romanos de Sevilla, Granada, Cádiz y Murcia. Madrid.

CME V. BLÁZQUEZ, J.M. (1982), Mosaicos romanos de la Real Academia de la Historia, Ciudad Real, Toledo, Madrid y Cuenca. Madrid.

CME VI. BLÁZQUEZ, J.M Y ORTEGO, T. (1982), Mosaicos romanos de Soria. Madrid.

CME VII. BLÁZQUEZ, J.M Y MEZQUÍRIZ, Ma A. (1985), Mosaicos romanos de Navarra. Madrid.

DE LOS RIOS, D. A. (1908), Catálogo de los monumentos históricos y artísticos de la provincia de Málaga. Málaga.

DE LOS SANTOS GALLEGO, S. (1977), "Excavaciones en la villa romana de Balazote (Albacete)", Segovia y la Arqueología Romana. Barcelona, pp. 367-370.

DE NUCCIO, M. y UNGARO, L. (2002), I Marmi colorati della Roma imperiale. Venecia.

DWEYER, E. J. (1982), Pompeian Domestic Sculpture. A study of five Pompeian Houses and their contents. Roma.

DUNBABIN, K.M.D. (1994), "The use of private space" en DUPRÉ, X. (coord), La ciutat en el món romà : Actes XIV Congrés Internacional d'Arqueologia Clàssica, Tarragona, 5-11/9/1993. Tarragona, pp. 165-176.

FERNÁNDEZ CASTRO, M ${ }^{\mathrm{a}}$ C. (1982), Villas romanas en España. Madrid.

FERNÁNDEZ GALIANO, D. (1984), Complutum (II) Mosaicos. Excavaciones Arqueológicas en España. Madrid, pp. 137-138.

FERNÁNDEZ OCHOA, C.; MORILLO CERDÁN, A., y ZARZALEJOS PRIETO, M. (2000). "Grandes conjuntos termales públicos en Hispania" en FERNÁNDEZ OCHOA, C. y GARCÍA ENTERO, V. (eds.), Termas romanas en el Occidente del Imperio. II Coloquio Internacional de Arqueología en Gijón 1999, pp. 59-72.

FERNÁNDEZ OCHOA, C. y GARCÍA ENTERO, V. (eds.). (2000), Termas romanas en el Occidente del Imperio, II Coloquio Internacional de Arqueología en Gijón 1999. Gijón.

FRESNEDA PADILLA, E., TORO MOYANO, I.,PEÑA RODRÍGUEZ, J.P., GÓMEZ BENITO, R. y LÓPEZ LÓPEZ, M. (1991), "Excavación arqueológica en la villa romana de la calle Primavera (Granada)" AAA 3, pp. 141-156.

FORNELL MUÑOZ, A. (2005), "Las villae romanas en la Andalucía Mediterránea y el estrecho". Jaén.

GARCÍA BUENO, C. (1994), "Mosaicos de la Puente de la Olmilla (Albaladejo, Ciudad Real)", Veleia 11, pp. 95-116.

GIMÉNEZ REYNA, S., GARCÍA Y BELLIDO, A. (1948), "Antigüedades romanas de Antequera", AEspA 21, pp. 48-69.

GORGES, J. G. (1979), Les Villas Hispano-Romaines, Paris.

GOZALBES CRAVIOTO, C. (1984), Las vías romanas de Málaga. Madrid.

GREIFENHAGEN, A. (1957), Griechiesche Eroten. Berlín.

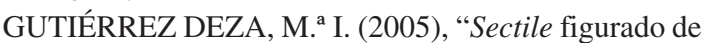
la villa de la Estación de Antequera”. Mainake 27, pp. 379-394.

HAYES, J.W. (1972), Roman Late Pottery. Londres.

HIDALGO PRIETO, R. (1991), "Mosaicos con decoración geométrica y vegetal de la Villa romana de El Ruedo (Almedinilla, Córdoba), AAC 2, pp. 325-361.

JACOPI, B. (1943), "Scavi in prossimità del Porto Fluviale di S. Paolo, località di Pietra Papa". Monumenti Antichi XXXIX, pp. 1-178.

JIMÉNEZ SALVADOR, J.L. y MARTÍN-BUENO, M. (1992), La Casa del Mitra (Cabra, Córdoba). Cabra.

KAPOSSY, B. (1969), Brunnenfiguren der hellenistischen und römischen Zeit. Zürich.

KOPPEL, E.M. (1995), "La decoración escultórica de las villae romanas", en NOGUERA CELDRÁN, J.M., Poblamiento rural romano en el sureste hispano. Murcia, pp. 27-48.

LAMBOGLIA, N. (1950), Gli scavi di Albintimilium e la cronologia della ceramica romana. Campagne di scavo 1938-1940. Bordighera.

LEÓN ALONSO, P. (2001), Retratos romanos de la Bética. Sevilla.

LEÓN ALONSO, P. (1995), Esculturas de Itálica. Sevilla.

LÓPEZ MONTEAGUDO, G. (1998), "Sobre una particular iconografía del triunfo de Baco en dos mosaicos romanos de la Bética” AAA 9, pp. 191-222. 
LOZA AZUAGA, M L. (1993), "Notas sobre la colocación de esculturas decorativas en el mundo romano. A propósito de una estatua-fuente de Alameda". Estudios dedicados al Alberto Balil in memoriam. Málaga, pp. 175-183.

MELERO GARCÍA, F. y ROMERO PÉREZ, M. (2001), "Estudio numismático de la Villa romana de la Estación. Antequera. Málaga" Revista de Estudios Antequeranos 12, pp. 259-270.

NOGALES BASARRATE, T. y GONÇALVES, L.J (eds). (2004), Actas de la IV Reunión sobre Escultura Romana en Hispania. Madrid.

NOGALES BASARRATE, T., CARVALHO, A. y ALMEIDA, M.J. (2004), "El programa decorativo de la Quinta das Longas (Elvas, Portugal): un modelo excepcional de las villae de la Lusitania" en NOGALES BASARRATE, T. y GONÇALVES, L.J., Actas de la IV Reunión sobre Escultura Romana en Hispania. Madrid, pp. 103-156.

NOZAL, M. CORTÉS, J. y ABÁSOLO, J.A. (2000), "Intervenciones arqueológicas en los Baños de la Villa de la Olmeda. Pedrosa de la vega, Palencia" en FERNÁNDEZ OCHOA, C. y GARCÍA ENTERO, V (eds), Termas romanas en el Occidente del Imperio, II Coloquio Internacional de Arqueología en Gijón. Gijón, pp. 311-318.

PERCIVAL, J. (1988), The Roman Villa. An historical introduction. Londres.

POSAC MON, C. Y RODRÍGUEZ OLIVA, P. (1979), "La Villa romana de Sabinillas (Manilva)", Mainake 1 1979, pp. 129-145.

PUERTA, C., ELVIRA, M. A. y ARTIGAS, T. (1994), "La colección de esculturas hallada en Valdetorres del Jarama" AEspA 67, pp. 179-200.

REIS, M ${ }^{\mathrm{a}} \mathrm{P}$. (2004), Las termas y "balnea" romanos de Lusitania, Studia lusitana 1. Madrid.
RIGGSBY, A.M. (1997), "Public and private in Roman culture: the case of the cubiculum". JRA 10, pp. 36-56.

RODRÍGUEZ DE BERLANGA, M. (1903), Catálogo del Museo Loringiano. Málaga.

RODRIGUEZ OLIVA, P. (1993), "El símbolo de Melpómene. Teatro y muerte en la España romana". Estudios dedicados a Alberto Balil in memoriam. Málaga, pp. 49-83.

RODRÍGUEZ OLIVA, P. (2004), "Miscelánea de esculturas de la Bética, en NOGALES BASARRATE, T. y GONÇALVES, L. J., Actas de la IV Reunión sobre Escultura Romana en Hispania. Madrid, pp. 52-47.

ROMERO PÉREZ, M y; MELERO GARCÍA, F. (2001), "La villa romana de la Estación. Antequera. Málaga" Revista de Estudios Antequeranos 12, pp. 235-258.

SALADO ESCAÑO, J.B. (2005), "La Villa romana de Benagalbón, Málaga. Primera descripción”. Mainake XXVII, pp. 353-378.

SERRANO RAMOS, E. (1991), Terra Sigillata Hispánica de los alfares de Singilia Barba. Málaga.

TRILLMICH, W. (coord) (1993), Hispania Antiqua. Die Denkmäler der Römerzeit. Mainz am Rheim.

TORTORELLA, S. (1981), "Produzione D" Atlante delle Forme Ceramiche I. EAA. Roma, pp. 78-117.

VAQUERIZO, D. (1990), La decoración escultórica de "El Ruedo" (Almedinilla, Córdoba). AAC 1, 1990, pp. 125-154.

VAQUERIZO, D. y NOGUERA, J.M. (1997), La Villa de El Ruedo (Almedinilla, Córdoba). Decoración escultórica e interpretación. Murcia.

WREDE, H. (1986), "Pan and Lederhalfter" $R M$ 93, pp. 189-210.

Recibido el 13-06-06 Aceptado el 10-09-06 